\title{
Small artificial impoundments have big implications for hydrology and freshwater biodiversity
}

Robert Morden, Water, Agriculture and Environment program, The University of Melbourne, robert.morden@unimelb.edu.au

Avril C Horne, Water, Agriculture and Environment program, The University of Melbourne, avril.horne@unimelb.edu.au

Nick Bond, Centre for Freshwater Ecosystems, La Trobe University, Wodonga, Victoria, Australia; N.Bond@latrobe.edu.au

Rory Nathan, Water, Agriculture and Environment program, The University of Melbourne, rory.nathan@unimelb.edu.au

Julian D. Olden, School of Aquatic and Fishery Sciences, University of Washington, Seattle, Washington, United States, olden@uw.edu

This paper is a non-peer reviewed preprint submitted to Earth ArXIV.

The paper has been submitted to Frontiers in Ecology and the Environment 
Small artificial impoundments have big implications for hydrology and freshwater biodiversity

\section{Authors}

Robert Morden, University of Melbourne, Victoria, Australia; ORCID: 0000-0001-8293-5640

Avril Horne, University of Melbourne, Victoria, Australia; ORCID: 0000-0001-6615-9987

Nick Bond, Centre for Freshwater Ecosystems, La Trobe University, Wodonga, Victoria, Australia; ORCID: 0000-0003-4294-6008

Rory Nathan, University of Melbourne, Victoria, Australia; ORCID: 0000-0001-7759-8344

Julian D. Olden, School of Aquatic and Fishery Sciences, University of Washington, Seattle, Washington, United States; ORCID: 0000-0003-2143-1187

\section{Keywords}

Farm dams, farm ponds, small waterbodies, headwater streams, hydrological stress, freshwater biodiversity, unregulated streams

\section{Abstract}

Headwater streams are critical for freshwater ecosystems. Global and continental studies consistently show major dams as dominant sources of hydrological stress threatening biodiversity in the world's major rivers, but cumulative impacts from small artificial impoundments concentrated in headwater streams have rarely been acknowledged. Using the Murray Darling River basin (Australia) and the Arkansas River basin (USA) as case studies, we examine the hydrological impact of small artificial impoundments. The extent of their influence is significant, altering hydrology in $280-380 \%$ more waterways when compared to major dams alone. Hydrological impacts are concentrated in smaller streams (catchment area $<100 \mathrm{~km}^{2}$ ), raising concerns that the often diverse and highly endemic biota found in these systems may be under threat. Adjusting existing biodiversity planning and management approaches to address the cumulative effects of many small and widely distributed artificial impoundments presents a rapidly emerging challenge for ecologically sustainable water management.

In a nutshell:

- Recent studies have highlighted the implications of large dams for river hydrology and their potential impacts on biodiversity. However, these studies have overlooked the role of small artificial impoundments (SAIs).

- Case studies are used to show that SAls can be a major source of hydrological stress. The downstream impact of SAls on flow regimes is similar to the impact of a single impoundment with the same aggregate capacity and watershed.

- Whereas major dams predominantly affect major rivers, SAls predominantly affect small waterways, including small headwater streams that have been hailed as critical for freshwater biodiversity.

\section{Introduction}

Headwater streams play a paramount role in maintaining hydrologic connectivity, harboring biodiversity, and supporting ecosystem integrity (Colvin et al. 2019). Despite this, debates continue over the implementation of policies and regulations seeking to protect these waters from 
burgeoning human enterprise. In a high-profile example, a 2015 update of the 'Waters of the United States' (WOTUS) rule would have qualified both perennial and smaller nonperennial waterways in the United States for water quality protections (Marshall et al. 2018), but implementation of this update was halted in 2019 and further scaling back of the definition of WOTUS was signed in 2020. Such regulatory actions in the United States and elsewhere, run in contrast to a large and growing body of literature supporting the social and ecological value of headwater streams (Meyer et al. 2003; Clarke et al. 2008; Colvin et al. 2019), and mounting threats to these ecosystems caused by smaller dams and other regulating infrastructure.

Past and planned construction of small-to-medium dams is unprecedented. Recent estimates report that the number of small-to-medium on-channel dams (ca. 82,891$)$ vastly outnumber large dams around the world, and that hundreds of thousands of additional small hydropower plants may be installed to meet future energy demands (Couto and Olden 2018; Lange et al. 2019). Indeed, many more dams are expected to be built in coming decades due to the increasing global demand for hydropower, water security, and food security (Zarfl et al. 2014). The widespread ecological damage and loss of important goods and services caused by large dams is well recognized (Sabater et al. 2018; Poff 2019; Tickner et al. 2020). One recent study concluded that close to two-thirds (63\%) of major global waterways have significantly reduced connectivity primarily caused by in-channel large dams, and to a lesser extent by a range of other anthropogenic factors such as urbanization and floodplain structures, while the remaining one-third (37\%) are considered 'free flowing' (Grill et al. 2019).

A conspicuous omission from all global assessments of river regulation by dams (eg. Nilsson et al. 2005; Zarfl et al. 2014; Grill et al. 2019) is that headwater streams - while not directly impacted by large on-stream dams-remain at significant risk from the impacts of smaller dams and artificial ponds within the catchment. These smaller diffuse sources of hydrologic interception (referred to here as small artificial impoundments or 'SAls', but often known as 'farm ponds', 'farm dams', or 'small storages' - refer Panel 1) have received far less recognition. Awareness of the impact of smaller dams and waterbodies on hydrology and biodiversity has emerged in recent years, including the cumulative effects of dams built to support hydropower production (Walter and Merritts 2008; Couto and Olden 2018; Lange et al. 2019; Couto et al. 2021) and agriculture practices (Renwick et al. 2006; Downing 2008; Nathan and Lowe 2012).

The scope of SAI impacts are challenging to characterize at a continental or global scale due to a lack of data regarding their number and locations in many regions (Januchowski-Hartley et al. 2020). Consequently, they are often ignored in investigations into the effects of flow alteration on freshwater ecosystems, with research and policy attention instead focusing on large in-channel structures and major extractions. In doing so, such studies make an implicit assumption that the biggest ecological impacts arise from the largest individual extractions or impoundments, rather than considering the totality of hydrological stresses in operation, including those associated with the cumulative effects of SAls.

This paper examines the relative role of SAls and larger on-stream dams in causing hydrological stress throughout a catchment, and the challenges associated with the management, and supporting policy, of SAls into the future. Impoundments of all types can affect upstream and downstream biodiversity through multiple pathways, for example by altering habitat conditions (Agoramoorthy et al. 2016; Biggs et al. 2017), water quality (Renwick et al. 2006; Ibrahim and Amir-Faryar 2018), and waterway connectivity (Leitão et al. 2018; Barbarossa et al. 2020); here, we focus on the threat to downstream biodiversity using a hydrological measure of the degree of impoundment. We look to Australia and the United States to demonstrate how we continue to underestimate the risk posed to global biodiversity from hydrological alteration, particularly in headwater streams, by continuing to ignore the widespread, growing number and cumulative impact of SAls. 
Panel 1 - What are small artificial impoundments (SAIs)?

The wide range of different terms for waterbodies distributed throughout catchments is a common source of confusion (Biggs et al. 2017). Small natural impoundments are usually called 'ponds' or 'lakes', whereas small artificial impoundments are called 'farm ponds', 'farm storages', 'small storages', 'tanks', 'stock ponds', or 'mill ponds' and are usually constructed with a low earthen bank across a watercourse or landscape depression.

Local differences may also exist - in Australia small artificial impoundments are usually called 'farm dams' (Nathan and Lowe 2012), but other terms such as 'floodplain storage', 'catchment dam' or 'runoff dam' are sometimes used to help identify the primary source of the water. In Europe, the term 'small waterbodies' appears to be a more common label when referring to a wide range of features such as storages, mill ponds, and ditches (Biggs et al. 2017).

In this paper we adopt the term 'small artificial impoundments' or 'SAls' as it appears the most precise and least ambiguous terminology. SAls included in our analysis ranged over 400-fold in size from as little as $250 \mathrm{~m}^{2}$ up to more than $100,000 \mathrm{~m}^{2}$. In our case study, SAls are typically constructed for agricultural and livestock purposes, with a smaller number managed for hydropower, recreation, aquaculture, or potable supply. Some examples of SAls from around the world highlighting their diversity of size and construction techniques are shown in Figure 1.

\section{Magnitude of hydrological stress}

Global assessments of the impacts of on-stream dams have reported the 'degree of regulation' (DoR), defined by the ratio of the total capacity of upstream storages with the average annual flow at a given location in the river network (Nilsson et al. 2005; Grill et al. 2019). DoR is a useful surrogate measure of potential threat to biodiversity, with dam induced flow changes shown to act synergistically with other impacts from dam modification, e.g. sediment flux, geomorphic alteration, floodplain disconnection and fragmentation of river corridors (Poff et al. 2007; Grill et al. 2014). While DoR is a simple metric and does not describe individual components of the flow regime, it does provide a consistent quantitative measure of the potential for hydrological stress that can be readily mapped (Lehner et al. 2011; Grill et al. 2014).

To understand the role of SAls in contributing to hydrological stress throughout a catchment, the DoR concept was applied to two case studies, the Murray Darling River Basin, Australia, and the Arkansas River Basin, United States. These basins were selected as exemplars of the longstanding challenges facing global rivers subjected to SAls. The Murray Darling basin is the largest river basin in Australia covering more than one million square kilometres, supplying drinking water to more than three million people and generating roughly $40 \%$ of Australia's total agricultural production. The Arkansas River basin, the second longest tributary of the Mississippi River, encompasses close to a half million square kilometres, and supports substantial irrigated agricultural production.

The DoR was calculated for all reaches - defined as the segments between tributaries - in the river network for both case study basins, in the first instance considering only major on-stream dams, and then accounting for the presence of SAls. A threshold to identify impacted rivers is difficult to estimate with any confidence. For comparative purposes, a DoR value of $16.7 \%$ has been adopted based on a recent global study of the impact of large storages (Grill et al. 2019). See Supporting Information for calculation methods.

Differences in estimates of degree of regulation are striking. In the Murray Darling River Basin, when considering only major on-stream storages (Figure 2a) we find that around $10 \%$ of reaches by length are flow impacted (Figure $2 \mathrm{~b}$ ). But when SAls are included, the proportion of impacted streams in the basin almost quadruples to $37 \%$, with impacted streams represented across almost the entire 
basin. SAls only represent $7 \%$ of total storage capacity, yet their influence increases the relative length of impacted waterways by $380 \%$ compared to the extent of impacts from large storages. Similarly, in the Arkansas River basin, 3.5\% of reaches by length are impacted by major on-stream dams (Figure 2c), but when SAls are included this proportion nearly triples to 9.7\% (Figure 2d). SAls only represent $0.03 \%$ of total storage capacity, yet they increase the relative length of impacted waterways by $280 \%$.

Climate is an important driver of the results reported here. Areas with mean annual rainfall higher than approximately $1000 \mathrm{~mm}$ have sufficiently high rates of runoff that the DoR rarely exceeds $16.7 \%$ even with high levels of SAI development. Conversely, areas with less than around $400 \mathrm{~mm}$ have such low runoff that even the presence of a small number of SAls could results in high estimates of DoR. However, these areas tend to have relatively low levels of SAI development, most likely because a combination of low runoff and high evaporation make open water impoundments impractical for most agricultural purposes.

Hydrological modelling also revealed that the effects of SAls on downstream flow regimes are broadly similar to the effects of large dams. Using one Murray Darling River Basin site as an example, the effect on downstream flow regime of a hypothetical large dam was compared to a large number of SAls with the same aggregate capacity and watershed (Figure 3). The overall percentage reduction in annual flow was somewhat higher for SAls than for a single large storage, but the net effect on flow exceedance and numbers of low flow days were very similar. Another four sites modelled in the same way showed comparable results (see Supporting Information for modelling methods and results for other catchments). In effect, if a large dam can be considered a source of flow regulation, then collections of SAls must be viewed as a form of 'distributed flow regulation'.

\section{Spatial comparison of impacted streams with biodiversity}

In both case study basins we found that SAls primarily affect smaller and headwater streams, and some instances these streams may have higher conservation priority because they support greater numbers of threatened species than waterways affected by large dams alone. This is particularly important, as first to third order streams make up to $80 \%$ of waterways in most basins (Colvin et al. 2019), and widespread threats to freshwater biodiversity globally (Tickner et al. 2020) highlight the need to protect and restore precisely these types of waterways.

Using the IUCN Red List of threatened species (IUCN 2019) as a key measure of biodiversity, we compared numbers of threatened species across waterways of different sizes (Figure 4) (see Supporting Information for analysis details). In both basins, almost all waterways impacted by major dams have a catchment area greater than $1000 \mathrm{~km}^{2}$. By contrast, approximately half of streams impacted by SAls have a catchment area less than $100 \mathrm{~km}^{2}$. For the Murray Darling River Basin, the proportion of SAI-affected waterways with high numbers of threatened species is much greater for smaller $\left(<100 \mathrm{~km}^{2}\right)$ compared to larger waterways $\left(>10,000 \mathrm{~km}^{2}\right)(32 \%$ and $7 \%$ of waterways respectively). For the Arkansas River Basin, the trend is reversed ( $21 \%$ and $50 \%$ of waterways respectively).

\section{Management challenges}

Across the globe there are ongoing efforts to restore biodiversity downstream of large dams. While these efforts are necessary to address the significant environmental impacts arising downstream from such structures (Tickner et al. 2020), our analysis suggests that river reaches downstream of large dams may potentially represent only a small fraction of all river reaches experiencing hydrologic stress. SAls vastly increased the length of waterways potentially subject to hydrological 
stress. Catchment and waterway management agencies are already overstretched and addressing the needs of the additional waterways impacted by SAls is undoubtedly a substantial task.

Challenges to current policy. While the case for controlling SAls to limit the risks to biodiversity may be apparent in some areas, there may also be a complex policy mosaic and considerable local resistance. Historically, in most parts of the world SAls could be built with little regulation or consideration of potential environmental impacts, although some jurisdictions have in recent years introduced controls on the construction of new SAls (Morris et al. 2019). This means that there is a tendency for many owners of SAls to consider them a 'right', and that any attempt to regulate or limit future development can be controversial (Horne et al. 2017). The large number of individual SAls requires consultation and engagement with an equally large number of individual owners. Also, because SAls serve a variety of purposes (Nathan and Lowe 2012) they become entwined in a range of policy areas including agricultural water supply (Wisser et al. 2010), essential domestic water supply, sediment control (Renwick et al. 2006; Ibrahim and Amir-Faryar 2018), fire management, and in some cases provision of critical habitat and refuges (Agoramoorthy et al. 2016; Biggs et al. 2017; Chen et al. 2019).

The dangers of cumulative impacts. When many individual landowners construct new SAls, their individual impacts may be negligible but their cumulative impacts can give rise to "the tyranny of small decisions" (Kahn 1966). Crucially, we have demonstrated that the storage capacity of an impoundment is not a good indicator of its potential impact, so a key challenge is to ensure that the cumulative impact of existing and future SAls is considered alongside larger dams (Couto and Olden 2018; Couto et al. 2021), other existing threats such as extractions, and other foreseeable future threats such as climate change and land use change (Athayde et al. 2019).

Incomplete understanding of the problem. Knowledge of the impacts of SAls requires, as a minimum, spatial data identifying waterbodies as small as $\sim 200 \mathrm{~m}^{2}$. This information does not exist for most parts of the world (McManamay et al. 2018), although there are some exceptions such as the United States NHD Plus High Resolution dataset (Moore et al. 2019) and several state datasets in Australia. One of the highest resolution global datasets is HydroLAKES (Messager et al. 2016) showing 1.42 million waterbodies, but even this is insufficient as the smallest identified features are around $10 \mathrm{ha}$, which is approximately the upper limit of SAls. The scale of data processing required to capture large numbers of very small features from remote sensing data makes generating new datasets a complex and expensive task.

Insufficient modelling tools to account for impact and assess management actions. A further issue is the difficulty in demonstrating the benefits of any remedial actions over long implementation periods (King et al. 2017). While a range of modelling tools for SAls do exist (Habets et al. 2018), some adaptation of these tools will be required to track impacts and the benefits of any planned management intervention. There has been some success in this regard in Australia, for example the Murray Darling Basin Plan (Australian Government 2012) includes SAls in its annual accounting processes alongside major dams as part of the overall consumptive pool. Considerable work has been undertaken to develop new water accounting and modelling approaches to make this possible (Srikanthan et al. 2015; Morden 2017).

\section{Moving forward}

Many global and continental scale studies ignore the impacts of SAls, making an implicit assumption that the biggest ecological impacts arise from the biggest extractions or impoundments. This paper has highlighted the dangers of this assumption, showing that whereas SAls have relatively small capacity, their large number and widespread distribution can result in substantial cumulative impacts. To ignore SAls is to underestimate the risk posed to biodiversity in smaller and headwater 
streams that are paramount to freshwater integrity (Colvin et al. 2019). Moving forward, significant investments into the development of new information systems that catalog SAls and implementation of environmental and hydrological monitoring is necessary. It is only with this data that SAls can be considered alongside other forms of anthropogenic extractions and held accountable for the hydrological impacts they generate.

\section{Acknowledgements}

RM was funded by an Australian Government Research Training Program Scholarship and an ARC DECRA award (DE180100550). AH was funded through an ARC DECRA award (DE180100550). We thank two anonymous reviewers for helpful suggestions, and Lisa Lowe and Chloe Wiesenfeld for contributing photos.

\section{References}

Agoramoorthy G, Chaudhary S, Chinnasamy P, and Hsu MJ. 2016. Harvesting river water through small dams promote positive environmental impact. Environ Monit Assess 188: 1-11.

Athayde S, Duarte CG, Gallardo ALCF, et al. 2019. Improving policies and instruments to address cumulative impacts of small hydropower in the Amazon. Energy Policy 132: 265-71.

Australian Government. 2012. Water Act 2007 - Basin Plan 2012, Extract from the Federal Register of Legislative Instruments (28 November 2012).

Barbarossa V, Schmitt RJP, Huijbregts MAJ, et al. 2020. Impacts of current and future large dams on the geographic range connectivity of freshwater fish worldwide. Proc Natl Acad Sci U S A 117: 3648-55.

Biggs J, Fumetti S von, and Kelly-Quinn M. 2017. The importance of small waterbodies for biodiversity and ecosystem services: implications for policy makers. Hydrobiologia 793: 3-39.

Chen W, He B, Nover D, et al. 2019. Farm ponds in southern China: Challenges and solutions for conserving a neglected wetland ecosystem. Sci Total Environ 659: 1322-34.

Clarke A, MacNally R, Bond N, and Lake PS. 2008. Macroinvertebrate diversity in headwater streams: A review. Freshw Biol 53: 1707-21.

Colvin SAR, Sullivan SMP, Shirey PD, et al. 2019. Headwater streams and wetlands are critical for sustaining fish, fisheries, and ecosystem services. Fisheries 44: 73-91.

Couto TBA, Messager ML, and Olden JD. 2021. Safeguarding migratory fish via strategic planning of future small hydropower in Brazil. Nat Sustain: 1-8.

Couto TB and Olden JD. 2018. Global proliferation of small hydropower plants - science and policy. Front Ecol Env 16: 91-100.

Downing JA. 2008. Emerging global role of small lakes and ponds: little things mean a lot. Limnetica 29: 9-24.

Grill G, Lehner B, Thieme M, et al. 2019. Mapping the world's free-flowing rivers. Nature 569: 21521.

Grill G, Ouellet Dallaire C, Fluet Chouinard E, et al. 2014. Development of new indicators to evaluate river fragmentation and flow regulation at large scales: A case study for the Mekong River Basin. Ecol Indic 45: 148-59.

Habets F, Molénat J, Carluer N, et al. 2018. The cumulative impacts of small reservoirs on hydrology: A review. Sci Total Environ 643: 850-67. 
Hijmans RJ, Cameron SE, Parra JL, et al. 2005. Very high resolution interpolated climate surfaces for global land areas. Int J Climatol 25: 1965-78.

Horne AC, Morris CR, Fowler KJA, et al. 2017. Management options to address diffuse causes of hydrologic alteration. In: Water for the Environment: From Policy and Science to Implementation and Management. Elsevier Inc.

Ibrahim YA and Amir-Faryar B. 2018. Strategic insights on the role of farm ponds as nonconventional stormwater management facilities. J Hydrol Eng 23: 04018023.

IUCN. 2019. The IUCN Red List of Threatened Species. Version 2019-1. <http//www.iucnredlist.org> Downloaded 2 April 2019.

Januchowski-Hartley SR, Mantel S, Celi J, et al. 2020. Small instream infrastructure: Comparative methods and evidence of environmental and ecological responses. Ecol Solut Evid 1.

Kahn AE. 1966. The tyranny of small decision: market failures, imperfections, and the limits of economics. Kyklos 19: 23-47.

King A, Nally R Mac, Thompson RM, and Poff NL. 2017. Legacies, lags and long - term trends : Effective flow restoration in a changed and changing world.

Lange K, Wehrli B, Åberg U, et al. 2019. Small hydropower goes unchecked. Front Ecol Environ 17: 256-8.

Lehner B, Liermann CR, Revenga C, et al. 2011. High-resolution mapping of the world's reservoirs and dams for sustainable river-flow management. Front Ecol Environ 9: 494-502.

Leitão RP, Zuanon J, Mouillot D, et al. 2018. Disentangling the pathways of land use impacts on the functional structure of fish assemblages in Amazon streams. Ecography (Cop) 41: 219-32.

Marshall JC, Acuña V, Allen DC, et al. 2018. Protecting U.S. temporary waterways (J Sills, Ed). Science (80-) 361: 856-7.

McManamay RA, Griffiths NA, DeRolph CR, and Pracheil BM. 2018. A synopsis of global mapping of freshwater habitats and biodiversity: implications for conservation. In: Pure and Applied Biogeography. InTech.

Messager ML, Lehner B, Grill G, et al. 2016. Estimating the volume and age of water stored in global lakes using a geo-statistical approach. Nat Commun 7: 1-11.

Meyer JL, Kaplan LA, Newbold D, et al. 2003. Where rivers Are born: The scientific imperative for defending small streams and wetlands. American Rivers, Sierra Club.

Moore RB, McKay LD, Rea AH, et al. 2019. User's guide for the national hydrography dataset plus (NHDPlus) high resolution.

Morden R. 2017. A new method of accounting for runoff dams. In: Syme G, Hatton MacDonald D, Fulton B, Piantadosi J (Eds). MODSIM2017, 22nd International Congress on Modelling and Simulation. Hobart, Australia.

Morris CR, Stewardson MJ, Finlayson BL, and Godden LC. 2019. Managing cumulative effects of farm dams in southeastern Australia. J Water Resour Plan Manag 145: 05019003.

Nathan R and Lowe L. 2012. The hydrologic impacts of farm dams. Australas J Water Resour 16: 7583.

Nilsson C, Reidy CA, Dynesius M, et al. 2005. Fragmentation and flow regulation of the world's large river systems. 308: 405-8.

Poff NL. 2019. A river that flows free connects up in 4D. Nature 569: 201-2.

Poff NL, Olden JD, Merritt DM, and Pepin DM. 2007. Homogenization of regional river dynamics by 
dams and global biodiversity implications. Proc Natl Acad Sci U S A 104: 5732-7.

Renwick WH, Sleezer RO, and Smith S V. 2006. Small artificial ponds in the United States: impacts on sedimentation and carbon budget. In: Proceedings of the Eighth Federal Interagency Sedimentation Conference (8thFISC),. Reno, Nevada.

Sabater S, Bregoli F, Acuña V, et al. 2018. Effects of human-driven water stress on river ecosystems: a meta-analysis. Sci Rep 8.

Srikanthan R, Barua S, and Hafeez M. 2015. Estimating volume of water harvested by farm dams in Murray-Darling Basin. In: 21st International Congress on Modelling and Simulation. Gold Coast, Australia.

Tickner D, Opperman JJ, Abell R, et al. 2020. Bending the curve of global freshwater biodiversity loss: An emergency recovery plan. Bioscience 70: 330-42.

Walter RC and Merritts DJ. 2008. Natural streams and the legacy of water-powered mills. Science (80- ) 319: 299-304.

Wisser D, Frolking S, Douglas EM, et al. 2010. The significance of local water resources captured in small reservoirs for crop production - A global-scale analysis. J Hydrol 384: 264-75.

Zarfl C, Lumsdon AE, Berlekamp J, et al. 2014. A global boom in hydropower dam construction. Aquat Sci 77: 161-70.

Figure 1: Examples of small artificial impoundments around the world (a) Victoria, Australia (credit: Lisa Lowe), (b) Virginia, USA (credit: Chesapeake Bay Program, source: Flickr.com, license: CC BY 2.0), (c) Tasmania, Australia (credit: Chloe Wiesenfeld) (d) Kampheng Phet, Thailand (credit: François Molle; source: Flickr.com, license: CC BY 2.0).

Figure 2: Impoundments and the downstream waterways in which they cause hydrologic stress (a) locations of major on-stream dams and small artificial impoundments (SAIs) in the Murray Darling River basin, (b) streams with a Degree of Regulation (DoR) greater than 16.7\% in the Murray Darling River basin, (c) locations of the major on-stream dams and SAls in the Arkansas River basin, and (d) streams with a DoR greater than $16.7 \%$ in the Arkansas River basin. Precipitation data: WorldClim (Hijmans et al. 2005).

Figure 3: Comparison of impacts of a single large dam and multiple small dams, including (a) impacts on total annual flows, (b) impacts on percent of low flow days, and (c) impact on daily flow percentiles. Note that in panels (b) and (c) the orange line is mostly hidden by the blue dash line. In each scenario, streamflow from a single gauge location (above shows Mt Ida Creek, Victoria, Australia, gauge 406226, catchment area $174 \mathrm{~km}^{2}$ ) was used as a hypothetical 'natural' flow, and the hydrological impact of impoundments was applied to this. The single large dam was set to capacity of $20 \%$ of mean annual flow ( $D \circ R=20 \%$ ) with an upstream watershed area $50 \%$ of the gauged catchment. The multiple small dams were set to capacity of $2500 \mathrm{~m}^{3}$ each, with the same aggregate capacity and watershed area as the single large dam. 
Figure 4: Total numbers of threatened freshwater species (IUCN red list) in waterways affected (degree of regulation $>16.7 \%$ ) by large dams or large dams plus small artificial impoundments (SAIs), aggregated by catchment area and reach length. (a) Murray Darling River basin with large dams only (b) Murray Darling River basin with large dams plus SAls (c) Arkansas River basin with large dams only (d) Arkansas River basin with large dams plus SAls. 


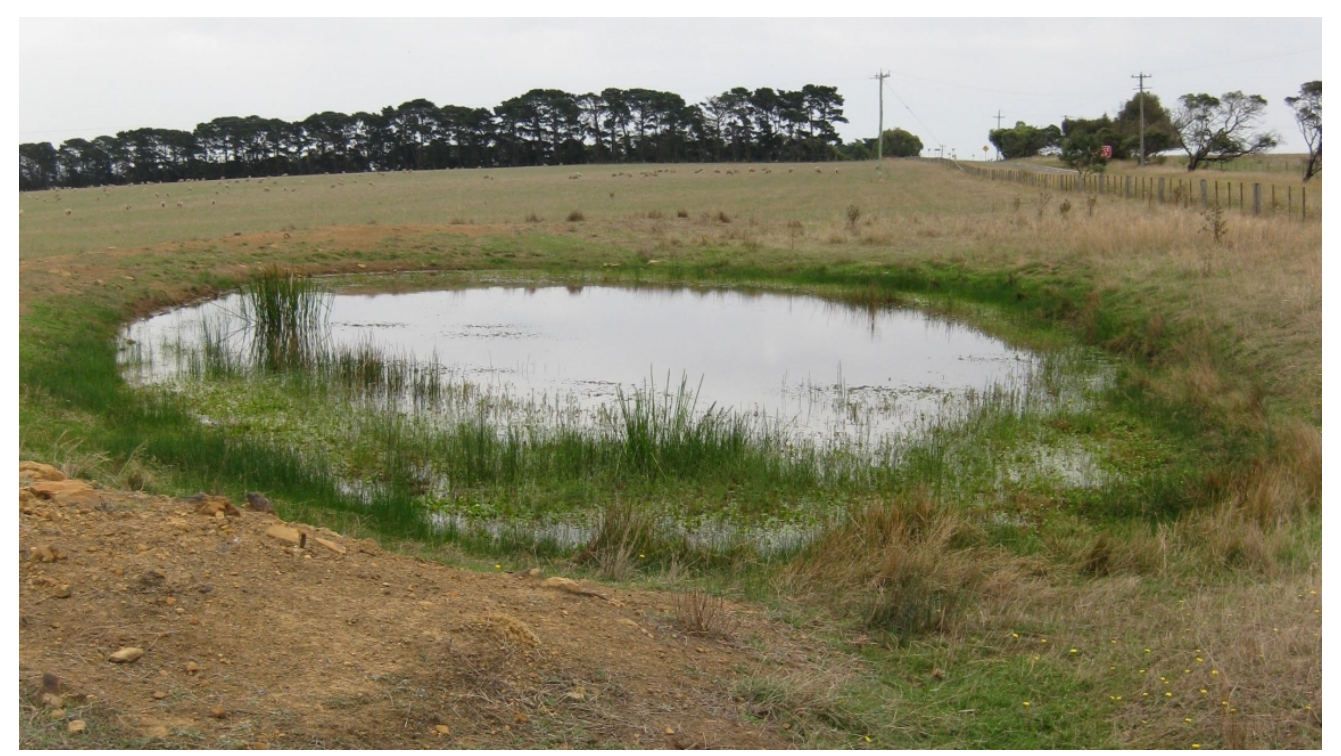

Figure 1: Examples of small artificial impoundments around the world (a) Victoria, Australia (credit: Lisa Lowe), (b) Virginia, USA (credit: Chesapeake Bay Program, source: Flickr.com, license: CC BY 2.0), (c) Tasmania, Australia (credit: Chloe Wiesenfeld) (d) Kampheng Phet, Thailand (credit: François Molle; source: Flickr.com, license: CC BY 2.0).

$297 \times 167 \mathrm{~mm}(180 \times 180 \mathrm{DPI})$ 


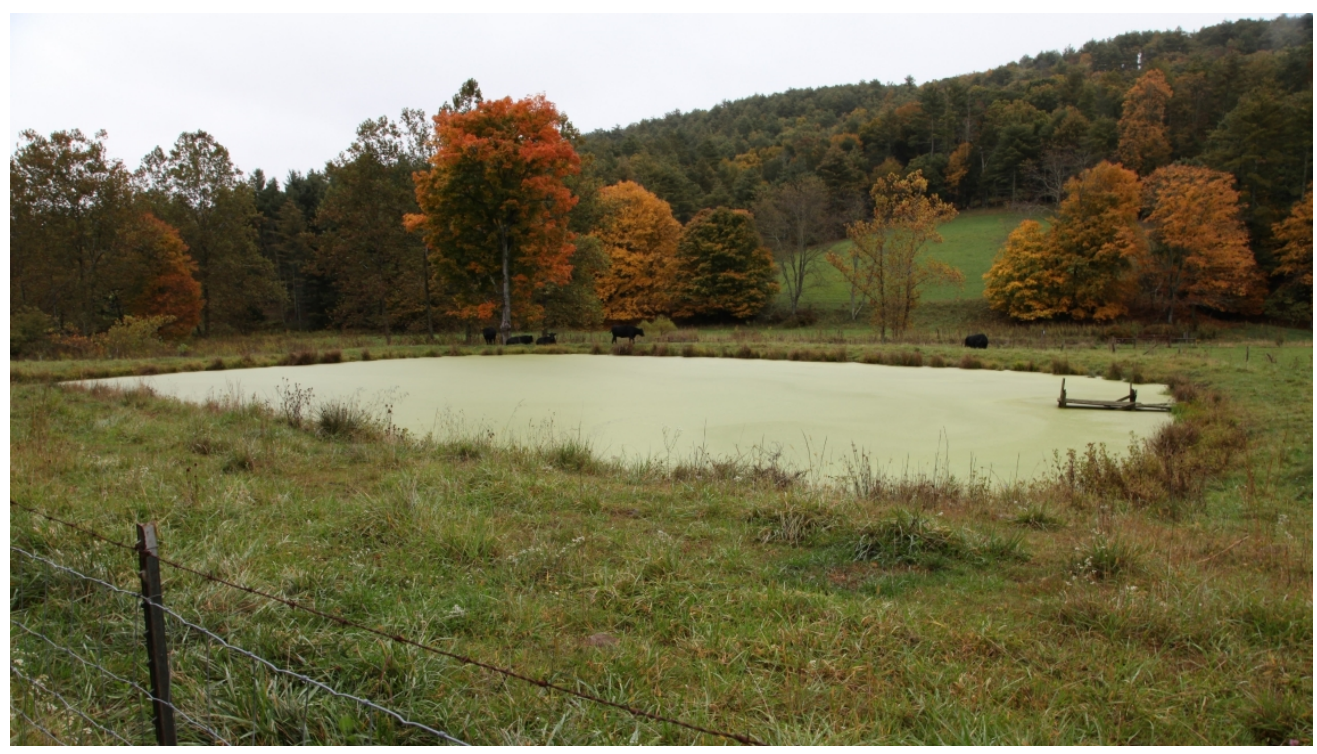

Figure 1: Examples of small artificial impoundments around the world (a) Victoria, Australia (credit: Lisa Lowe), (b) Virginia, USA (credit: Chesapeake Bay Program, source: Flickr.com, license: CC BY 2.0), (c) Tasmania, Australia (credit: Chloe Wiesenfeld) (d) Kampheng Phet, Thailand (credit: François Molle; source: Flickr.com, license: CC BY 2.0). 


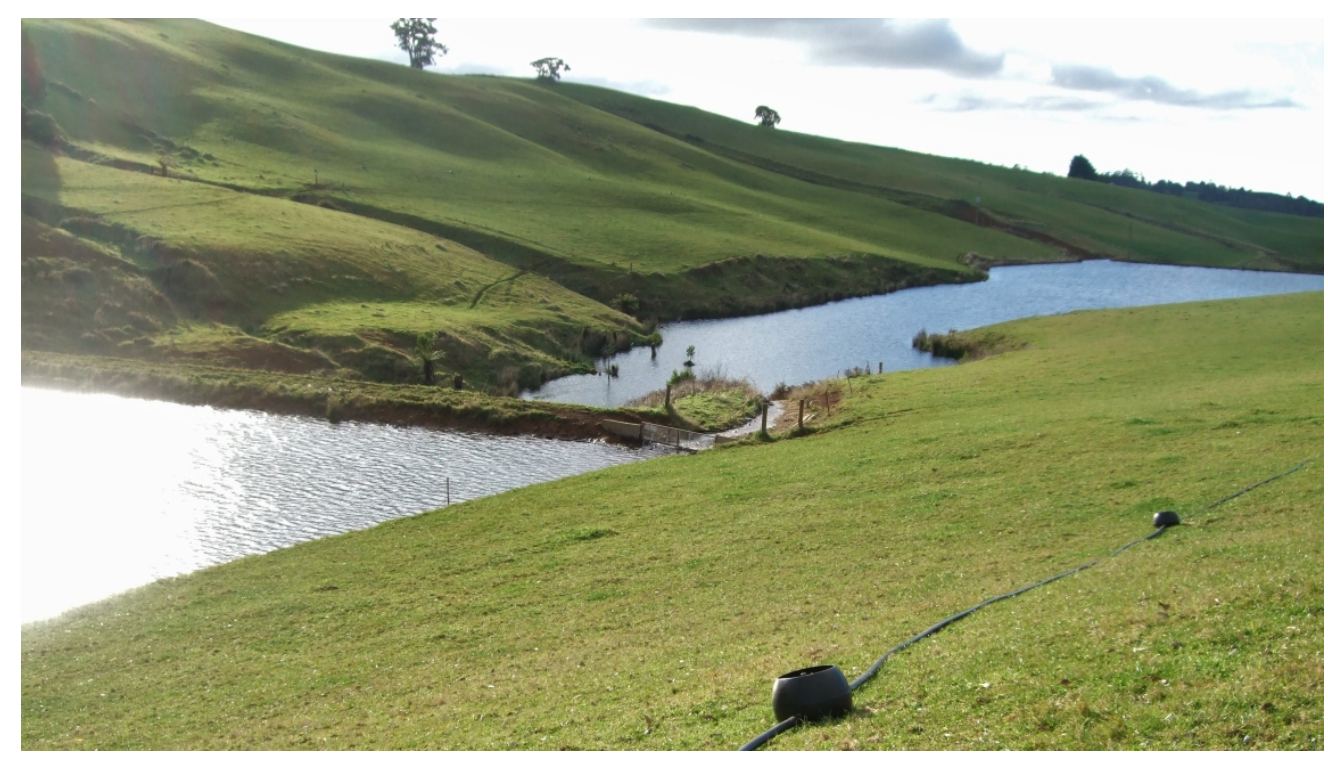

Figure 1: Examples of small artificial impoundments around the world (a) Victoria, Australia (credit: Lisa Lowe), (b) Virginia, USA (credit: Chesapeake Bay Program, source: Flickr.com, license: CC BY 2.0), (c) Tasmania, Australia (credit: Chloe Wiesenfeld) (d) Kampheng Phet, Thailand (credit: François Molle; source: Flickr.com, license: CC BY 2.0). 


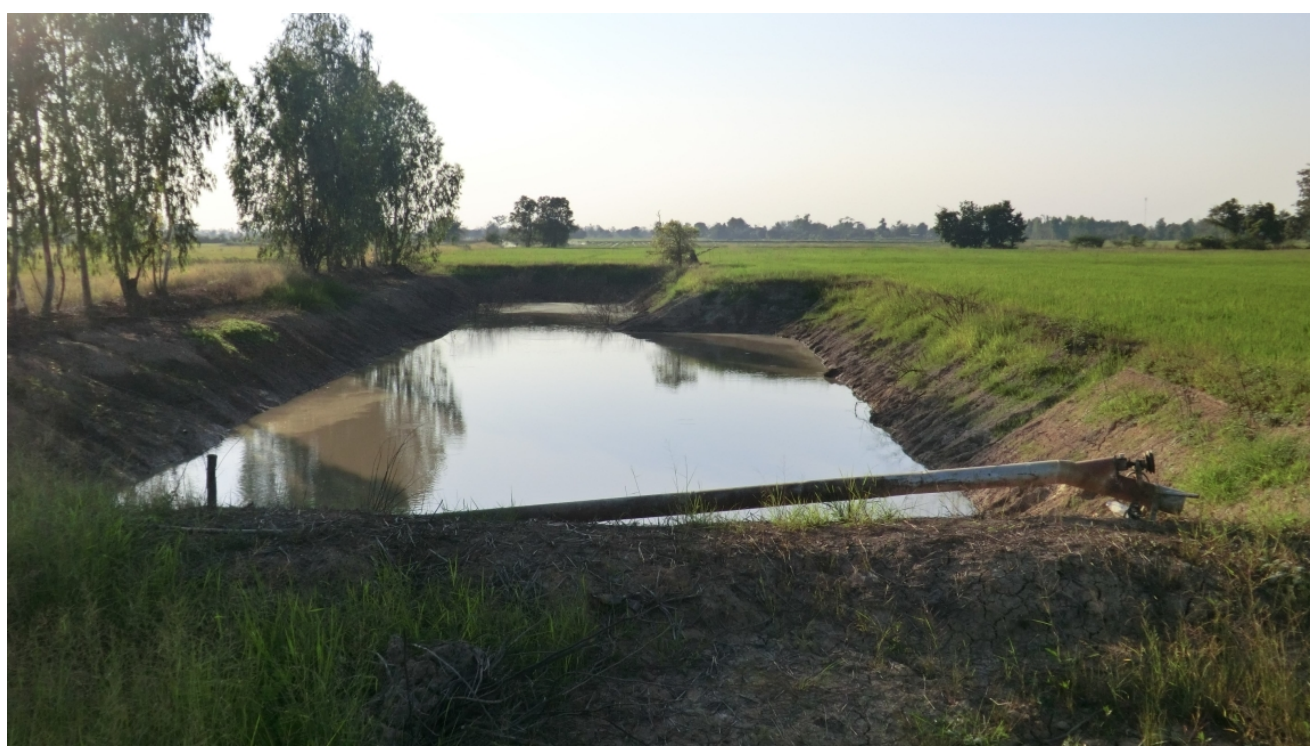

Figure 1: Examples of small artificial impoundments around the world (a) Victoria, Australia (credit: Lisa Lowe), (b) Virginia, USA (credit: Chesapeake Bay Program, source: Flickr.com, license: CC BY 2.0), (c) Tasmania, Australia (credit: Chloe Wiesenfeld) (d) Kampheng Phet, Thailand (credit: François Molle; source: Flickr.com, license: CC BY 2.0). 
(a)

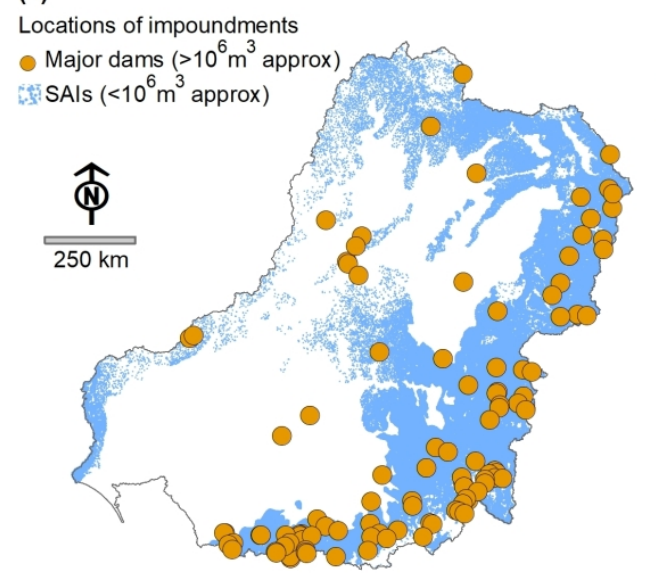

(c)

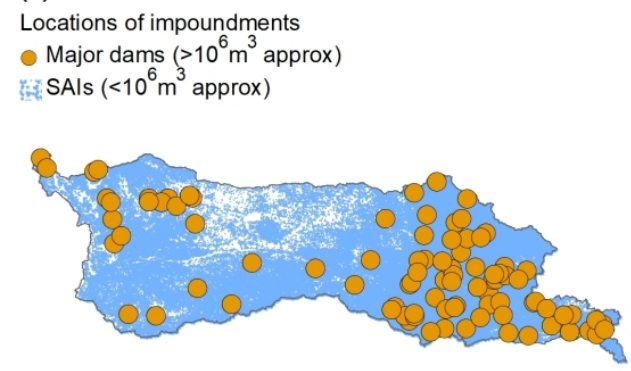

(b)

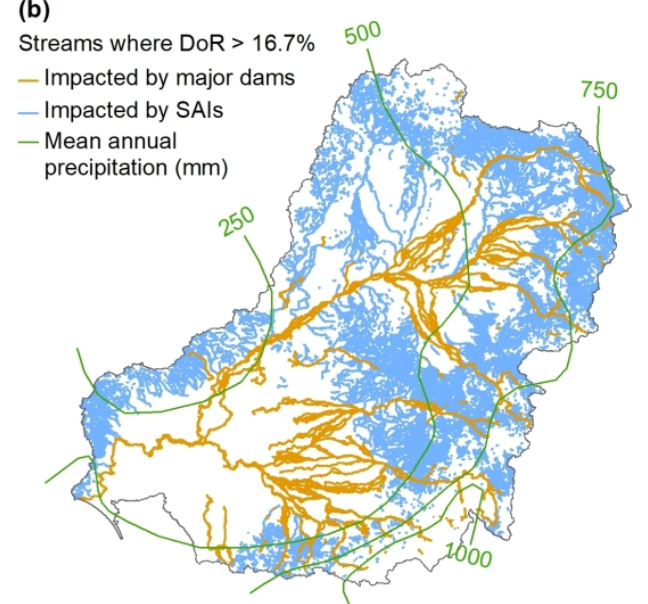

(d)

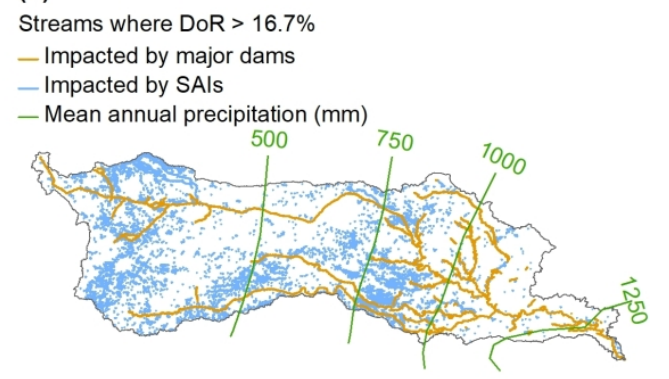

Figure 2: Impoundments and the downstream waterways in which they cause hydrologic stress (a) locations of major on-stream dams and small artificial impoundments (SAIs) in the Murray Darling River basin, (b) streams with a Degree of Regulation (DoR) greater than 16.7\% in the Murray Darling River basin, (c) locations of the major on-stream dams and SAIs in the Arkansas River basin, and (d) streams with a DoR greater than $16.7 \%$ in the Arkansas River basin. Precipitation data: WorldClim (Hijmans et al. 2005). 
(a) Total reduction in annual flows

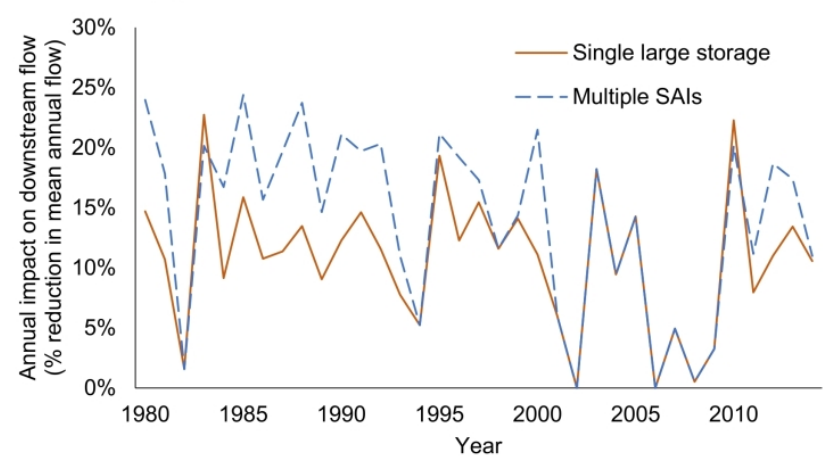

(b) Percent of low flow days

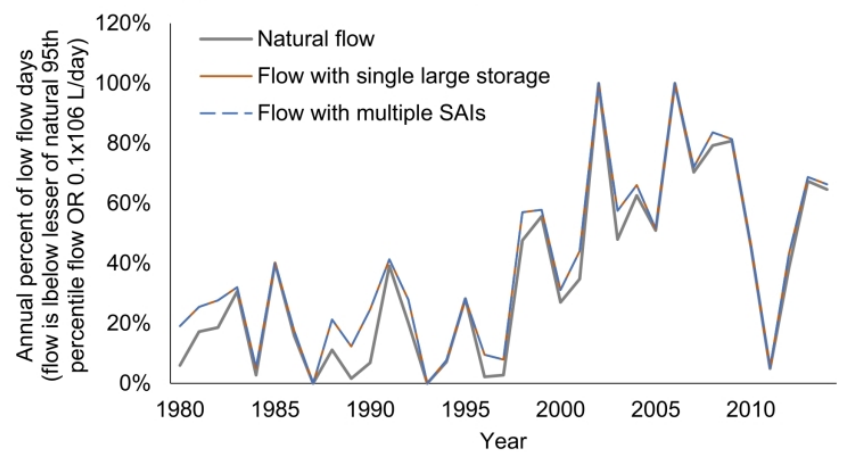

(c) Daily flow percentiles

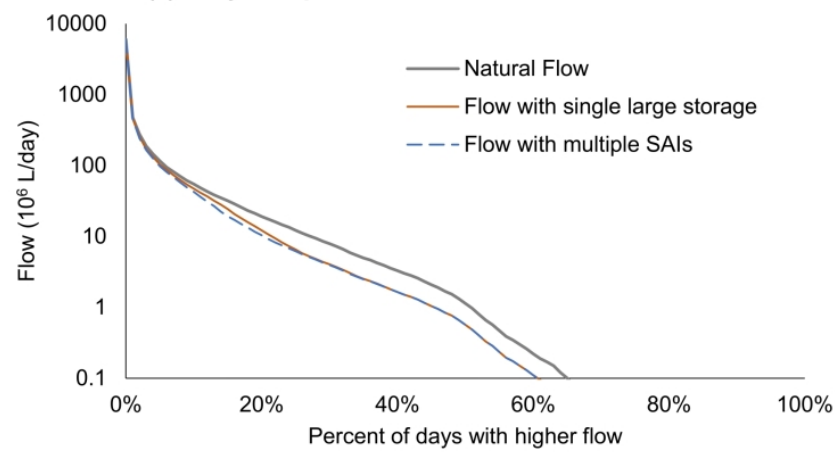

Figure 3: Comparison of impacts of a single large dam and multiple small dams, including (a) impacts on total annual flows, (b) impacts on percent of low flow days, and (c) impact on daily flow percentiles. Note

that in panels (b) and (c) the orange line is mostly hidden by the blue dash line. In each scenario, streamflow from a single gauge location (above shows Mt Ida Creek, Victoria, Australia, gauge 406226, catchment area $174 \mathrm{~km}^{2}$ ) was used as a hypothetical 'natural' flow, and the hydrological impact of impoundments was applied to this. The single large dam was set to capacity of $20 \%$ of mean annual flow (DoR $=20 \%$ ) with an upstream watershed area $50 \%$ of the gauged catchment. The multiple small dams were set to capacity of $2500 \mathrm{~m}^{3}$ each, with the same aggregate capacity and watershed area as the single large dam. 
(a)

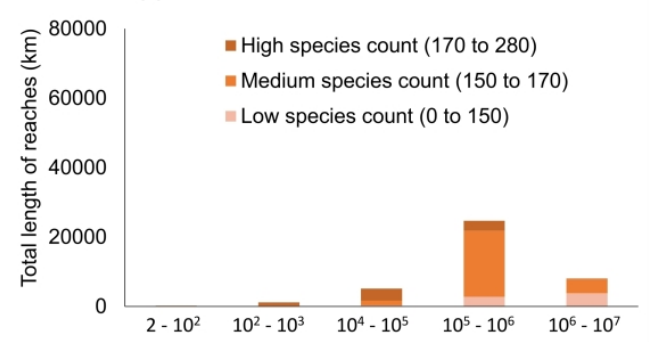

(c)

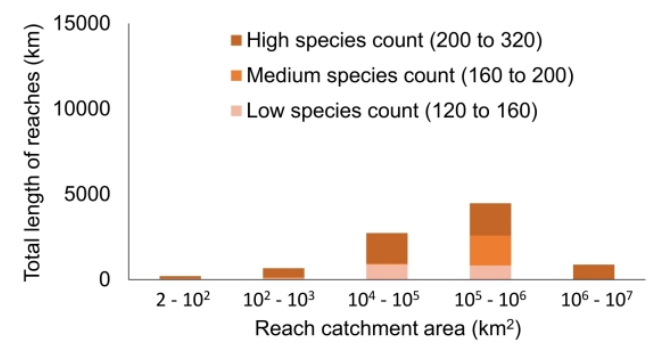

(b)

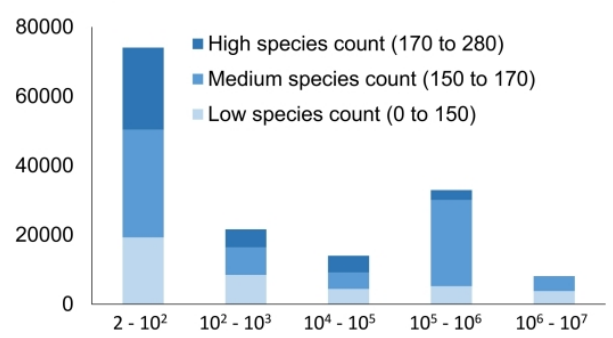

(d)

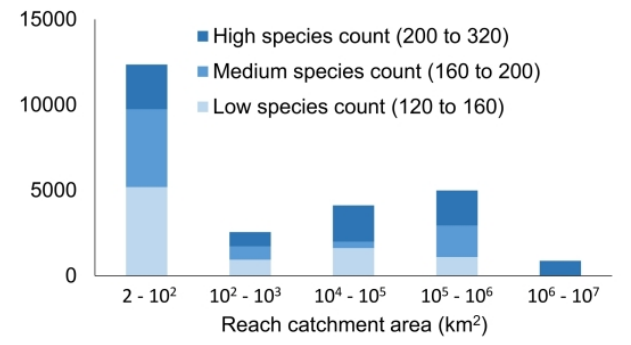

Figure 4: Total numbers of threatened freshwater species (IUCN red list) in waterways affected (degree of regulation $>16.7 \%$ ) by large dams or large dams plus small artificial impoundments (SAIs), aggregated by catchment area and reach length. (a) Murray Darling River basin with large dams only (b) Murray Darling River basin with large dams plus SAIs (c) Arkansas River basin with large dams only (d) Arkansas River basin with large dams plus SAIs.

$306 \times 187 \mathrm{~mm}(300 \times 300 \mathrm{DPI})$ 


\section{WebPanel S1. Details of analysis methods}

\section{Degree of Regulation (DoR)}

The Degree of Regulation (DoR) index is calculated for each reach in the network based on the cumulative upstream storage relative to the cumulative average annual discharge, with units of 'years'. A DoR value of 0.5 therefore implies the total upstream storage volume is equivalent to $50 \%$ the mean annual runoff, while a DoR of 3 implies 3 times (ie. 300\%) the mean annual flow can be captured or held in storages. Whilst having locally observed flow data is optimal for quantifying the many different facets of flow alteration, DoR is still a strong surrogate at broader spatial scales (Lehner et al. 2011; Grill et al. 2014). A number of thresholds have been used in the literature as indicative of potential downstream biological effects, ranging from 0.1 (Lehner et al. 2011) to 0.167 (Grill et al. 2019), which was the threshold adopted in the current study.

This index requires input data to characterize the impoundment locations and capacities, the river network, and the streamflow through the river network. Data sources for these key inputs are listed in WebTable S1 for each of the case study catchments.

\section{Impoundment information}

Not all waterbodies were included in calculations. In both case study catchments, natural waterbodies were excluded wherever they could be identified. Helpfully, the NHDPlus dataset (Moore et al. 2019) includes a field "FCODE" which clearly identifies many types of waterbodies. This field was used to specifically include only those features which were identified as a "reservoir" (FCODE=43600), "reservoir for storing water" (FCODE=43613 to 43621), or "lake/pond" (FCODE $=39000$ to 39012 ). Other features were excluded as either natural waterbodies, or artificial waterbodies with no connection to natural drainage (eg. sewerage pondage, tailings, etc.).

In the Murray Darling basin, some large impoundments were excluded if they were known to be offstream storages because their primary source of water is extraction from another storage or waterway rather than runoff from their immediate upstream watershed. Also, SAls were excluded across large parts of the basin where the average slope of the surrounding terrain was $0.25 \%$ ( 1 in 400 ) or flatter. In such areas, surface runoff is very unlikely to reach a waterway in natural circumstances, so small impoundments here are assumed to have no direct hydrological impact on a waterway.

In the Arkansas River basin continuous areas with average slope flatter than $0.25 \%$ do exist, but they are sufficiently small that filtering of SAls was not considered necessary.

The slope threshold of $0.25 \%$ was selected based on two criteria:

- Topographic data showing waterways at a scale of 1:250,000 (Geoscience Australia 2006) indicates that there are large parts of the Murray Darling basin where first to third order streams rarely occur. These areas broadly coincide with a regional slope of approximately $0.25 \%$ or flatter.

- In flatter portions of the Murray Darling basin SAls are constructed by excavating into flat ground or by building an enclosing embankment around the entire impoundment, whereas in steeper areas SAls are more commonly constructed by building an embankment across a waterway or a small fold in the landscape. This difference in construction technique underscores obvious differences in hydrological connectivity. While there is no distinct boundary between these two techniques, inspection of detailed aerial imagery suggests that a slope of $0.25 \%$ provides a reasonable lower bound of where the latter technique occurs. 
A range of data sources was used to estimate the capacity of impoundments. In the Murray Darling basin, capacities of major dams were assigned based on the published capacity in the Register of Large Dams in Australia (ANCOLD 2010), while the capacity of smaller impoundments was estimated based on a previously published equation based on surface area (Fowler et al. 2015), and subsequently included as an attribute of each waterbody in the published spatial data (Bunn et al. 2014).

In the Arkansas River basin, capacities of major dams were assigned based on the published capacity in the National Inventory of Dams (NID) (USACE 2019). For the majority of small impoundments, volumetric capacities are not known. However, the NID does record the surface area and capacity of some smaller impoundments in the study area. A new relationship between surface area and capacity was developed based on this data. Some filtering of the NID was required to obtain a meaningful relationship as follows:

- To ensure the relationship was applicable to smaller impoundments, only those with valid surface area and capacity values smaller than $300,000 \mathrm{~m}^{2}$ or $1 \times 10^{6} \mathrm{~m}^{3}$ were included.

- A small number of dams were found to have very shallow average depth, suggesting an unusual structure such as a shallow flood control dam. Only those with average depth greater than $0.3 \mathrm{~m}$ were included.

- The NID records surface areas in units of acres. In some cases, this value is sometimes recorded as an integer, leading to significant rounding errors if the surface area is less than 10 acres. Dams with surface area recorded as an integer less than or equal to 10 acres were excluded.

The surface area and volumetric capacity of all remaining features in the NID in the Arkansas River basin are shown in WebFigure S1, leading to an empirical relationship as follows:

$$
\mathrm{C}=1.91 \times \mathrm{SA}{ }^{0.986} \text { where } \mathrm{C}=\text { capacity in } \mathrm{m}^{3} \text { and } \mathrm{SA}=\text { surface area in } \mathrm{m}^{2} \text {. }
$$

The power form of this relationship is conceptually similar to those developed for SAls in other locations globally, including Australia, India, Africa, North America, and South America (Sawunyama et al. 2006; Venkatesan et al. 2011; Rodrigues et al. 2012; Fowler et al. 2015; Karran et al. 2017). This relationship was applied to all SAls where a published capacity was not available. Although there is considerable scatter in the raw data shown in WebFigure S1 suggesting the capacity of an individual impoundment can only be estimated with low accuracy, it should nevertheless provide a robust estimate of the combined capacity of a large number of SAls.

\section{River network information}

Stream connectivity data was available through the Australian Hydrological Geospatial Fabric (AHGF) (BoM 2012) for the Murray Darling basin, and the National Hydrography Dataset Plus High Resolution (NHDPlus HR) (Moore et al. 2019) for the Arkansas River. Throughout this study, these datasets were used to define each waterway 'reach' usually as the segment between tributaries, but sometimes also breaking a reach where there was a significant geomorphological change such as a large waterbody. There were over 150,000 reaches and 335,000 reaches in the Murray Darling and Arkansas River basins respectively.

All impoundments were assigned to a subcatchment and reach, and capacities were aggregated downstream and compared with mean annual flow to obtain the DoR. For both case study catchments, streams with a total upstream watershed less than $2 \mathrm{~km}^{2}$ were excluded from final results. 
We created simple hydrological models to compare the cumulative impacts on downstream flow regime due to large dams and SAls. Hydrological modelling of SAls is not common, but a handful of specialized algorithms and software packages do exist (Habets et al. 2018). For this analysis, we have used STEDI (Nathan and Lowe 2012; Fowler et al. 2015; Habets et al. 2018).

Very briefly, STEDI is a simple "fill and spill" water balance model to estimate the filling behavior of SAls and their hydrological impact relative to a downstream point in the river network. STEDI requires no calibration or parameterization, it is a purpose-built tool for calculating a water balance for each SAI at each timestep and aggregating the overall impact of all SAls combined. The fundamental water balance equation applied at each timestep (in this case daily) is as follows:

$\triangle S T O R A G E=I N F L O W+$ RAIN - EVAP - DEMAND - SPILL

The 'inflow' term is based on the flow at a downstream point in the river system, adjusted for respective catchment areas, usually obtained from observed flow records or separate rainfall runoff models. The 'rainfall' and 'evaporation' terms represent the climate acting directly on the surface of the water itself and are usually based on local climate records adjusted for the area of the water surface. The 'demand' term representing on-farm extractions is adjustable based on local conditions and is usually described as a set percentage of the impoundment capacity each year. The pattern of demand each timestep can be either a static value, a repeating annual pattern, or a longer timeseries of values.

Note that STEDI does not consider streamflow routing, in-stream losses, or seepage through the floor or walls of each impoundment. The model is able to provide a useful estimate of SAl impacts on downstream flow regimes in catchments where runoff generation can be assumed to be homogenous, and where routing and losses are not significant.

Two hypothetical scenarios were modelled for five catchments using STEDI. The first hypothetical scenario includes a single large storage in a catchment. In the second hypothetical scenario, the large storage is replaced by multiple $2500 \mathrm{~m}^{3}$ storages with the same aggregate capacity and the same aggregate inflows distributed equally between them. Each scenario was repeated for different locations in eastern Australia. These scenarios are shown schematically in WebFigure S2.

Hydrological data for each location was obtained from a range of sources. Streamflow data for each location was obtained online from publicly available government data services, while rainfall and evaporation were obtained for the catchment centroid from the SILO database (http://www.longpaddock.qld.gov.au/silo). To best represent evaporation from the surface of each dam, Morton evaporation over shallow lakes was adopted (McMahon et al. 2013). Key hydroclimate statistics and scenario information for each modelled location is presented in WebTable S2.

Using the STEDI software, extraction from each storage is also modelled. In all cases, the long term average annual extraction was set equal to $50 \%$ of the dam capacity, with daily pattern of extraction based on a rolling 2 week average of net evapotranspiration (Morton's actual evapotranspiration minus rainfall). This was adopted as an approximation of water demands for irrigation.

Inflow for each modelled storage was based on the total natural flow for the catchment, adjusted based on the simple ratio of total catchment area to the storage's upstream watershed. In other words, flow was assumed to be generated uniformly across the catchment.

For each site and each scenario, the impact of storages was calculated on a daily basis for the period from January 1980 to December 2014. WebFigure S3 compares the annual impacts on streamflows for the single dam and multiple dam scenarios, as well as the impact on low flows.

WebFigure S3 demonstrates that the annual volumetric impacts due to a single large storage is the same order of magnitude as for multiple SAls, although in most catchments the impacts of SAls tend to be higher. The effects on percent of low flow days are the same for both scenarios. The combined 
surface areas of all SAls was greater than the surface area of a single storage even though they had the same overall capacity, which is an expected consequence of the typical geometry of artificial impoundments. Higher rates of evaporation resulted in longer filling times for SAls, which is the most likely reason why the impacts of multiple SAls are often slightly higher with greater variability than single large storages.

This analysis clearly shows that the impact on the downstream flow regime is related to the combined capacity and upstream watershed areas of the storages. Small artificial impoundments within a catchment behave as a form of 'distributed flow regulation'. Note that the limitations of the STEDI model do not affect this conclusion: although STEDI does not represent streamflow routing or in-stream losses, these catchment processes are likely to affect all modelled scenarios in a similar manner regardless of the nature of the impoundments.

\section{Threatened species analysis}

To assess where large dams and SAls may have hydrological effects on biodiversity, we used the IUCN Red List spatial data (IUCN 2019) which shows the approximate ranges for each endangered species. As well as being an important biodiversity measure in its own right, the presence of threatened species also provides a broad proxy for species richness more generally. WebFigure S4 presents a 'heat map' showing how the number of threatened species varies considerably across each case study catchment.

Considerable data filtering and processing was required, as the global dataset includes many tens of thousands of species, the majority of which are not relevant to this study:

- Initially, only freshwater species with ranges in the case study catchments were selected, because the focus of this study is specifically freshwater biodiversity.

- Some of the species range polygons were attributed as "Extinct" or "Possibly extant". These were excluded to ensure that the final species list only included those which are known to currently exist in the study areas based on observation.

- Lastly, all records which were attributed as being "data deficient" or "not evaluated" were excluded. Also, some species are represented multiple times in the database, so to eliminate any double counting the remaining species polygons were dissolved to ensure that only one polygon remained for each species.

The number of species present across each case study catchment was calculated based on the count of species polygons present at the centroid of each AHGF catchment in the Murray Darling basin (167,682 catchments), and each NHDPlus HR catchment in the Arkansas River basin (897,087 catchments). Although the species range polygons are often relatively coarse and do not have this level of spatial accuracy, the goal was to ensure that every catchment (and therefore every reach) had a matching pair of values for DoR and number of threatened species.

\section{WebReferences}

ANCOLD. 2010. Register of Large Dams in Australia.

BoM. 2012. Australian Hydrological Geospatial Fabric (Geofabric).

Bunn SE, Kennard MJ, Bond NR, et al. 2014. Flow regimes and ecological assets. A technical report from the Ecological Responses to Altered Flow Regimes Flagship Research Cluster (SubProject 2). Melbourne, Australia.

Fowler K, Morden R, Lowe L, and Nathan R. 2015. Advances in assessing the impact of hillside farm 

dams on streamflow. Aust J Water Resour 19

Geoscience Australia. 2006. GEODATA TOPO 250K series 3.

Grill G, Lehner B, Thieme M, et al. 2019. Mapping the world's free-flowing rivers. Nature 569: 21521.

Grill G, Ouellet Dallaire C, Fluet Chouinard E, et al. 2014. Development of new indicators to evaluate river fragmentation and flow regulation at large scales: A case study for the Mekong River Basin. Ecol Indic 45: 148-59.

Habets F, Molénat J, Carluer N, et al. 2018. The cumulative impacts of small reservoirs on hydrology: A review. Sci Total Environ 643: 850-67.

IUCN. 2019. The IUCN Red List of Threatened Species. Version 2019-1. <http//www.iucnredlist.org> Downloaded 2 April 2019.

Karran DJ, Westbrook CJ, Wheaton JM, et al. 2017. Rapid surface-water volume estimations in beaver ponds. Hydrol Earth Syst Sci 21: 1039-50.

Lehner B, Liermann CR, Revenga C, et al. 2011. High-resolution mapping of the world's reservoirs and dams for sustainable river-flow management. Front Ecol Environ 9: 494-502.

McMahon TA, Peel MC, Lowe L, et al. 2013. Estimating actual, potential, reference crop and pan evaporation using standard meteorological data: a pragmatic synthesis. Hydrol Earth Syst Sci 17: 1331-63.

Moore RB, McKay LD, Rea AH, et al. 2019. User's guide for the national hydrography dataset plus (NHDPlus) high resolution.

Nathan R and Lowe L. 2012. The hydrologic impacts of farm dams. Australas J Water Resour 16: 7583.

Rodrigues LN, Sano EE, Steenhuis TS, and Passo DP. 2012. Estimation of small reservoir storage capacities with remote sensing in the Brazilian Savannah region. Water Resour Manag 26: 87382.

Sawunyama T, Senzanje A, and Mhizha A. 2006. Estimation of small reservoir storage capacities in Limpopo River Basin using geographical information systems (GIS) and remotely sensed surface areas: Case of Mzingwane catchment. Phys Chem Earth 31: 935-43.

USACE. 2019. National Inventory of Dams.

Venkatesan V, Balamurugan R, and Krishnaveni M. 2011. Establishing water surface area-storage capacity relationship of small tanks using SRTM and GPS. In: Energy Procedia. Elsevier. 
2

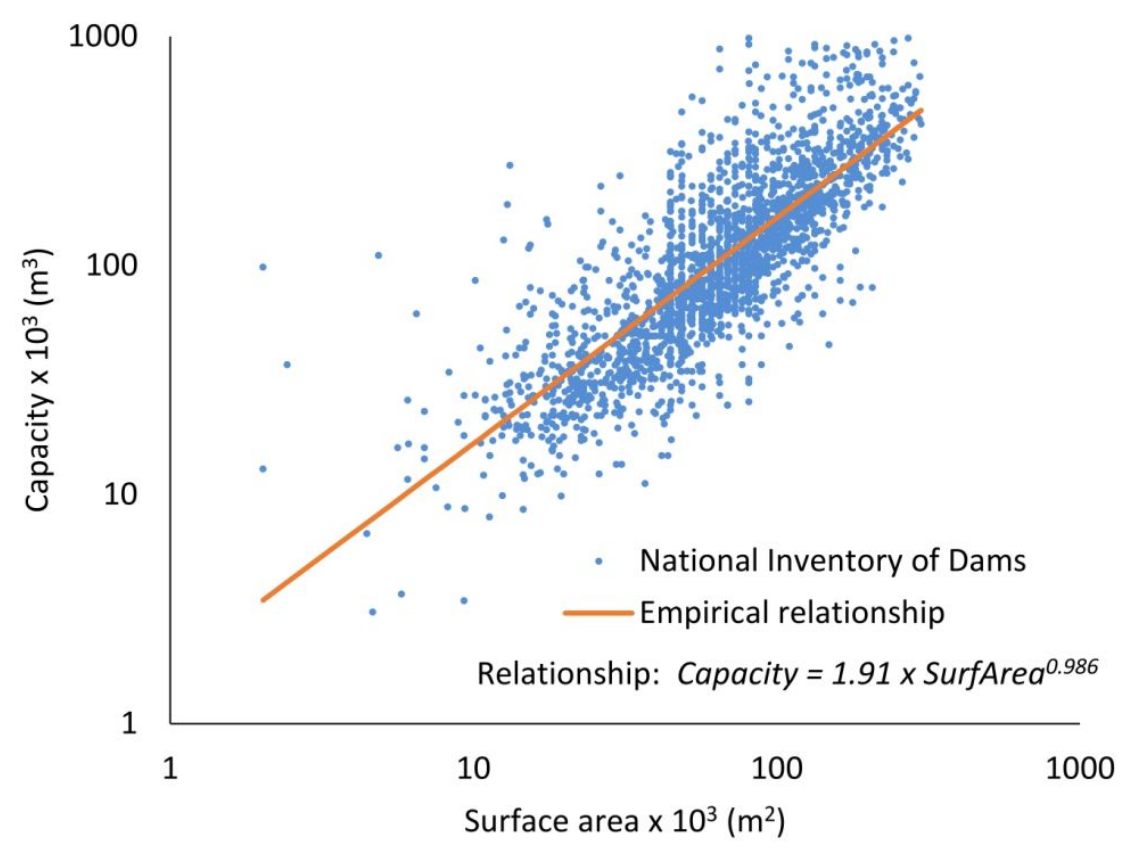

3

$4 \quad$ WebFigure S1: Developing an empirical relationship between the surface area and volumetric 5 capacity of impoundments included in the National Inventory of Dams (NID) in the Arkansas River 6 basin. Note that features were excluded if their capacity was greater than $300,000 \mathrm{~m}^{2}$, their surface 7 area was greater than $1 \times 10^{6} \mathrm{~m}^{3}$, or their average depth was less than $0.3 \mathrm{~m}$. Features were also 8 excluded if their surface area (acres) was published as an integer less than 10. 


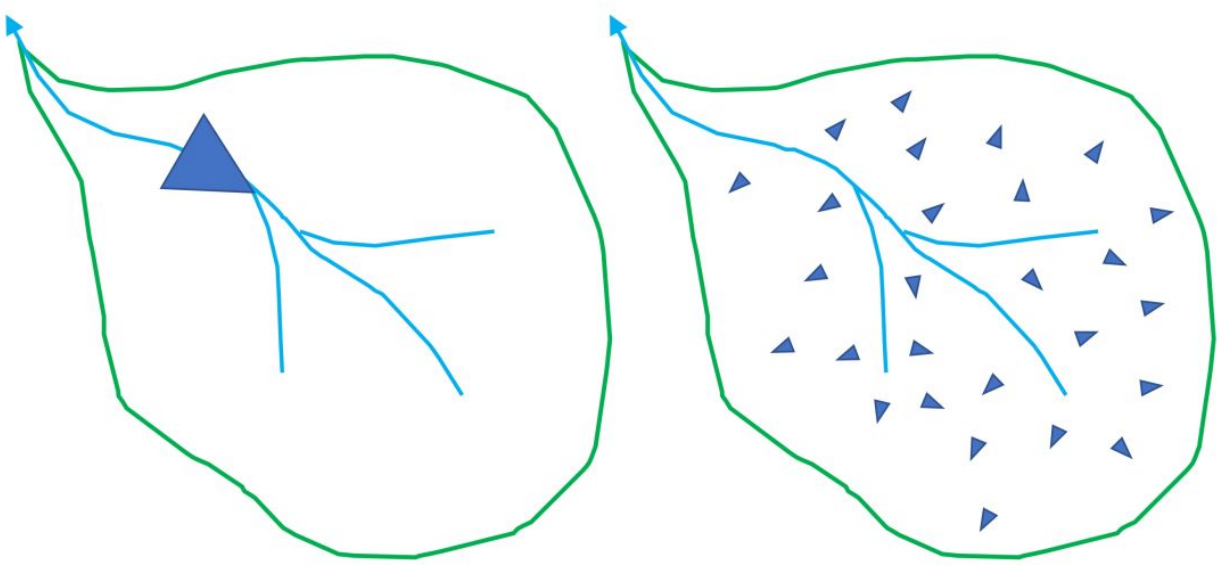

3

4 WebFigure S2: Schematic outline of the hydrological modelling scenarios using the STEDI small dam 5 modelling tool. On the left a single large storage with degree of regulation (DoR) $=20 \%$ is

6 impounding $50 \%$ of the overall catchment area, and on the right multiple $2500 \mathrm{~m}^{3}$ storages with

7 aggregate DoR $=20 \%$ are impounding $50 \%$ of the overall catchment area. 

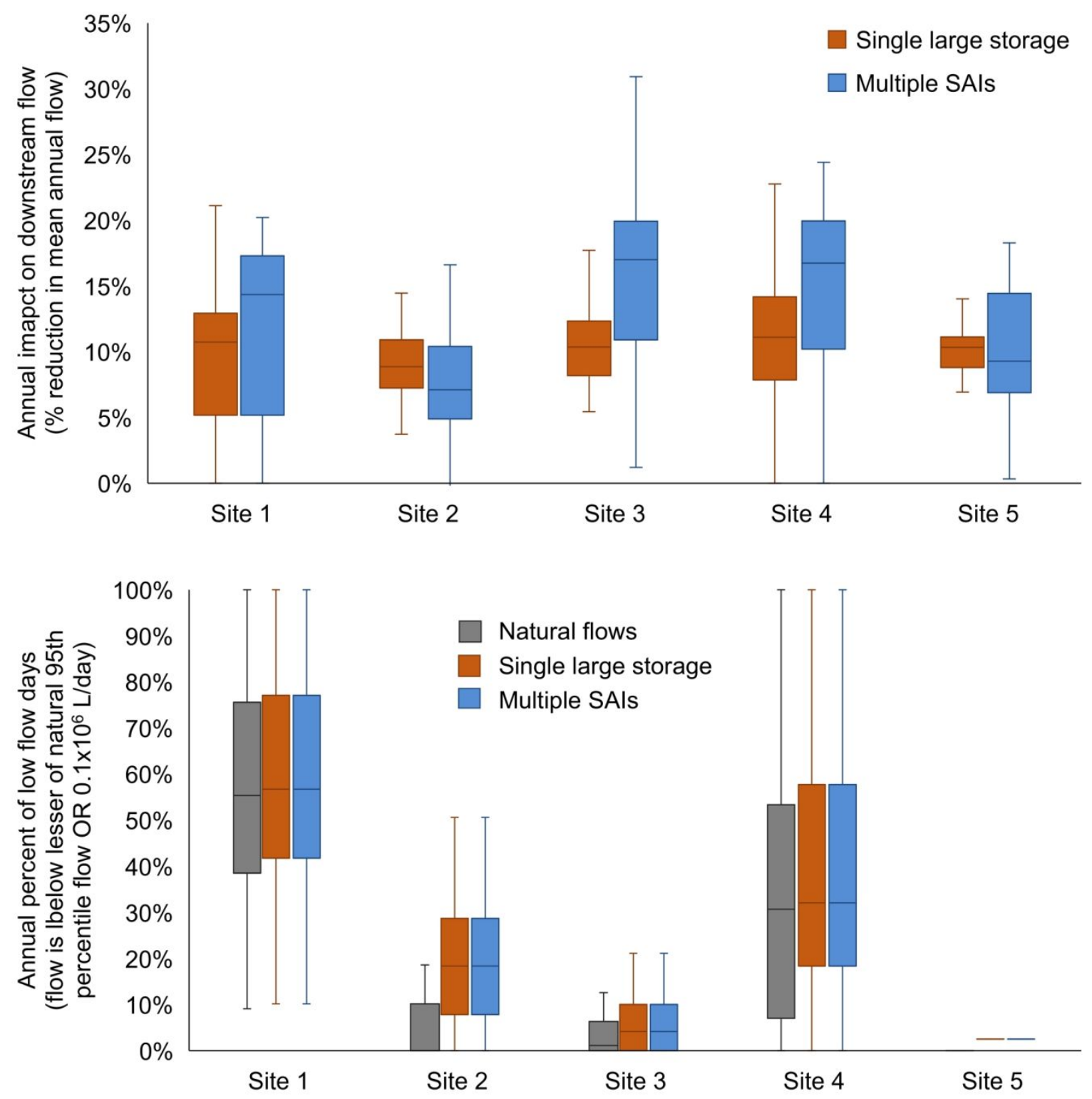

3

4 WebFigure S3: Impact in terms of annual reduction in flow (top panel) and annual percentage of low 5 flow days (lower panel), of a single large storage compared to multiple $2500 \mathrm{~m}^{3}$ storages with the 6 same overall capacity and upstream watershed, modelled over the period 1980 to 2014. Boxes 7 represent the $25^{\text {th }}$ and $75^{\text {th }}$ percentiles with a median line, and whiskers represent the $5^{\text {th }}$ and $95^{\text {th }}$ 8 percentiles of annual impacts. 
2

(a)

Number of threatened freshwater species

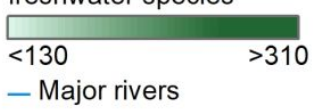

- Major rivers

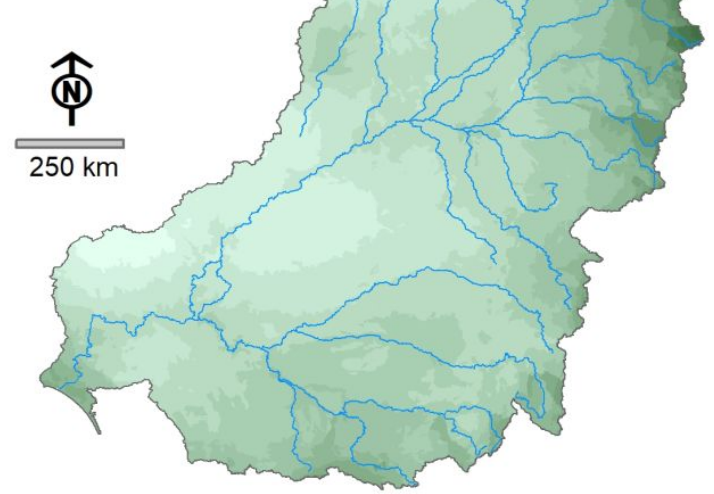

(b)

Number of threatened

freshwater species

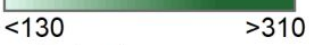

- Major rivers

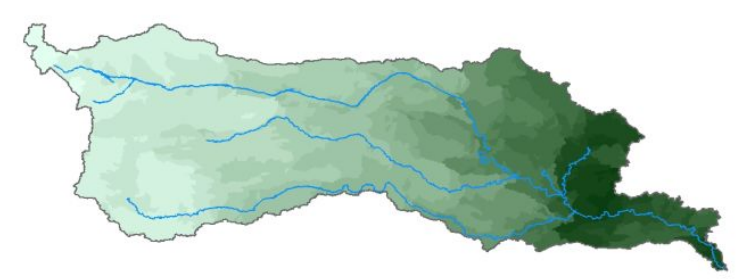

3

4 WebFigure S4: Numbers of threatened freshwater species across a) the Murray Darling basin and b) 5 Arkansas River basin based on IUCN Red List data (IUCN 2019), showing that threatened freshwater 6 species are not distributed uniformly across each basin. Data is based on the number of known 7 freshwater species ranges present at all locations across each river network.

8

\section{WebReferences}

IUCN. 2019. The IUCN Red List of Threatened Species. Version 2019-1. <http//www.iucnredlist.org> Downloaded 2 April 2019. 


\begin{tabular}{|c|c|c|c|}
\hline & & Murray Darling basin & Arkansas River \\
\hline \multirow[t]{2}{*}{$\begin{array}{l}\text { Dam } \\
\text { capacities }\end{array}$} & Major dams & $\begin{array}{c}\text { ANCOLD Register of large Dams in } \\
\text { Australia (ANCOLD 2010) }\end{array}$ & $\begin{array}{l}\text { National Inventory of Dams (USACE } \\
\text { 2019) }\end{array}$ \\
\hline & $\begin{array}{l}\text { Small artificial } \\
\text { impoundments } \\
\text { (SAls) }\end{array}$ & $\begin{array}{l}\text { Murray Darling Aquatic Assets } \\
\text { Geodatabase v2.0 (Bunn et al. } \\
\text { 2014) }\end{array}$ & $\begin{array}{c}\text { New capacity/surface area relationship } \\
\text { based on National Inventory of Dams } \\
\text { (USACE 2019) }\end{array}$ \\
\hline \multicolumn{2}{|c|}{ Dam and SAI locations } & $\begin{array}{l}\text { Murray Darling Aquatic Assets } \\
\text { Geodatabase v2.0 (Bunn et al. } \\
\text { 2014) }\end{array}$ & $\begin{array}{l}\text { NHD Plus High Resolution (Moore et al. } \\
\text { 2019) }\end{array}$ \\
\hline \multicolumn{2}{|c|}{ River network } & $\begin{array}{l}\text { Australian Hydrologic Geofabric } \\
\text { (BoM 2012) }\end{array}$ & $\begin{array}{l}\text { NHD Plus High Resolution (Moore et al. } \\
\text { 2019) }\end{array}$ \\
\hline \multicolumn{2}{|c|}{ Mean annual streamflow } & $\begin{array}{c}\text { Australian Geofabric } \\
\text { Environmental Attributes (Stein et } \\
\text { al. 2014) }\end{array}$ & $\begin{array}{l}\text { NHD Plus High Resolution (Moore et al. } \\
\text { 2019) }\end{array}$ \\
\hline
\end{tabular}

WebTable S1: Data sources for Degree of Regulation calculations

\section{WebReferences}

ANCOLD. 2010. Register of Large Dams in Australia.

BoM. 2012. Australian Hydrological Geospatial Fabric (Geofabric).

Bunn SE, Kennard MJ, Bond NR, et al. 2014. Flow regimes and ecological assets. A technical report from the Ecological Responses to Altered Flow Regimes Flagship Research Cluster (SubProject 2). Melbourne, Australia.

Moore RB, McKay LD, Rea AH, et al. 2019. User's guide for the national hydrography dataset plus (NHDPlus) high resolution.

Stein JL, Hutchinson MF, and Stein JA. 2014. A new stream and nested catchment framework for Australia. Hydrol Earth Syst Sci 18: 1917-33.

USACE. 2019. National Inventory of Dams. 


\begin{tabular}{|c|c|c|c|c|c|}
\hline & Site 1 & Site 2 & Site 3 & Site 4 & Site 5 \\
\hline Site name & $\begin{array}{c}\text { Concongella } \\
\text { Creek at } \\
\text { Stawell }\end{array}$ & $\begin{array}{c}\text { Franklin } \\
\text { River at } \\
\text { Toora }\end{array}$ & $\begin{array}{c}\text { Henry River } \\
\text { at Newton } \\
\text { Boyd }\end{array}$ & $\begin{array}{c}\text { Mount Ida } \\
\text { Creek at } \\
\text { Derrinal }\end{array}$ & $\begin{array}{c}\text { Running } \\
\text { Creek }\end{array}$ \\
\hline Gauge number & 415237 & 227237 & 204034 & 406226 & 402206 \\
\hline Mean annual flow $\left(10^{3} \mathrm{~m}^{3} / \mathrm{yr}\right)$ & 8185 & 21,675 & 46,050 & 10,365 & 29,600 \\
\hline Gauge catchment area $\left(\mathrm{km}^{2}\right)$ & 239 & 75 & 399 & 174 & 126 \\
\hline Mean annual rainfall (mm) & 537 & 1133 & 951 & 528 & 1169 \\
\hline Mean annual evaporation (mm) & 1163 & 998 & 1395 & 1224 & 1234 \\
\hline \multicolumn{6}{|c|}{ Single storage scenario } \\
\hline Capacity of single large storage $\left(10^{3} \mathrm{~m}^{3} / \mathrm{yr}\right)$ & 1637 & 4335 & 9210 & 2073 & 5920 \\
\hline Catchment area impounded $\left(\mathrm{km}^{2}\right)$ & 119.5 & 37.5 & 199.5 & 87 & 63 \\
\hline \multicolumn{6}{|c|}{ Multiple storage scenario } \\
\hline Number of $2500 \mathrm{~m}^{3}$ SAls & 655 & 1734 & 3684 & 829 & 2368 \\
\hline Catchment area impounded by each SAI ( $\left.\mathbf{k m}^{2}\right)$ & 0.182 & 0.022 & 0.054 & 0.105 & 0.027 \\
\hline
\end{tabular}

3 WebTable S2: Key data inputs and characteristics for each site used in the hydrological modelling 4 with the STEDI small dam modelling tool 


\section{Response to manuscript reviews}

\section{Manuscript ID FEE20-0366 [email ref: DL-SW-2-a]}

\section{Matt Hurteau}

Associate Editor

Frontiers in Ecology and the Environment

Dear Dr Hurteau,

We are pleased to re-submit our manuscript FEE20-0366 "Small artificial impoundments have big implications for hydrology and freshwater biodiversity" (revised title) for your consideration. We greatly appreciate the positive comments from all reviewers and welcome the opportunity to improve the manuscript based on their constructive feedback. The reviewer's suggestions were very helpful to highlight specific areas where the paper required additional clarification.

Our responses to the reviewer's comments are outlined below and have been highlighted with tracked changes in the revised manuscript alongside numerous other improvements. Please note that where we have indicated line numbers in the manuscript, we are referring to the clean version without tracked changes.

We believe that the manuscript has improved significantly by addressing the reviewer's comments and look forward to hearing from you in due course.

Regards,

Robert Morden

(on behalf of all authors) 


\section{Editorial comments}

1. Please submit each image component of Figure 1 as separate, high-resolution jpeg or tif files, named "Figure 1a", "Figure 1b", etc. Please remove the (a), (b), (c), (d) labels from the images, themselves.

2. In Figure 2, please enlarge all of the smallest text to improve readability. This primarily includes the green numbers and the numbers (especially superscripts) in the keys.

3. Please enlarge Figure 3 to have a resolution of at least $300 \mathrm{dpi}$ at a width of 4.5 inches. Please also ensure that the text is legible at this size. When resubmitting this figure, please supply as a jpeg or tif file.

4. For Figure 4, please sharpen the text and ensure that it is legible, as it is quite small. When resubmitting this figure, please supply as a jpeg or tif file.

5. Please rename "Box 1" in the main text as "Panel 1".

Thank you for these editorial comments. These issues have been resolved in the latest submission.

\section{Associate Editor}

\section{Comments to the Author}

This paper is very well-written, and the authors do an excellent job of highlighting an issue that many ignore: the cumulative ecological impacts of small artificial impoundments across watersheds. I generally agree with the positive responses from the two Reviewers, and I support Reviewer 1's mention that some limitations need to be discussed. This leads to:

My only major comment is that more methodological information is needed in the supplemental material to support the paper's findings. For example, in order to publish Figure 3 and WebFigure S2, additional details regarding the model are required. Some information is provided in WebPanelS1 but not nearly enough to support the study's findings. Please see my specific comments below regarding WebPanel S1. Also, please mention at least once in the main text some limitations to the findings (or "challenges" - however the authors wish to contextualize them) because they are, indeed, model outputs.

\section{We very much appreciate this feedback. WebPanel S1 in the revised manuscript now includes additional details of the hydrological modelling and its limitations, and further discusses how small artificial impoundments (SAIs) were identified and characterised in each study area. Our changes are further discussed below in response to the reviewer's comments.}

Somewhere in the paper, it would be worth mentioning that there are impacts beyond biodiversity, including water quality. It can be a quick mention, to be sure, since the paper is about biodiversity impacts.

\section{We agree with this comment and have now added text near line 83 in the revised manuscript to illustrate that the implications of small impoundments extend well beyond just biodiversity.}

Also, be careful to ensure the figures can stand independently. To do this, please edit the captions so that abbreviations used in the figures are spelled out in the captions. For example, in Webfigure S1, spell out DoR in the caption. 
This is an excellent suggestion. Changes have been made to almost all figures either improving the caption title or clearly defining abbreviations, in order to ensure that they are stand-alone and do not dependent on the main body of the text.

Webfigure S3 - This figure is a bit confusing. It's supposed to represent a gradient of impacts freshwater species, but the gradient is across the landscape - where they don't exist. Also, the caption doesn't seem to match the legend in the figure. I suggest only showing the gradient along the streams themselves and matching the caption and figure legend.

This is an excellent comment. On reflection, this figure could have been presented more clearly. The intention is to visually demonstrate that "threatened freshwater species are not uniformly distributed across each study area". Accordingly, the caption has been revised to include those exact words, and the legends changed accordingly. To reduce confusion, the figure no longer shows 'impacted' waterways, it simply displays major rivers to allow readers to understand the catchment physical layout.

The numbers of species are shown as a gradient across the entire landscape. This is a deliberate representation for the purposes of clarity. Each study area has hundreds of thousands of individual reaches and minor streams, which appear visually messy when plotted at this scale. This landscape representation was chosen to be smoother and clearer. The caption has been adjusted to better explain this representation.

\section{Webpanel S1}

Calculating DoR, lines 4-7 - Please be explicit here by providing units on the variables. If total volumetric (and please add "volumetric" in front of "capacity") capacity of impoundments is L3, and the long-term average annual streamflow is L3 T-1, then the index would be in T? The figures suggest it's a percentage, not a time unit.

Correct, the units of this index are indeed 'years'. We have clarified this point in WebPanel S1 line 5.

Line 14 - Provide the average slope in \% for better interpretability and add why that slope was chosen.

We agree that this number has been presented in a somewhat arbitrary manner. Further discussion of the basis for this part of the analysis have been provided in WebPanel S1 lines 33 to 44 .

Lines 17-20 - What were the specific criteria for "some large waterbodies" being excluded? Please detail that here.

We are very grateful for this comment, it has highlighted an oversight in our original wording when we were considering another river basin in the United States. In fact, no large dams were required to be excluded based on the National Inventory of Dams. The relevant text has been removed.

The revised manuscript now clearly states that large dams in the Arkansas River basin were included/excluded based on data provided in the NHDPlus dataset. Details of this process have been provided in WebPanel S1 lines 18 to 23.

Line 32: Is 1.91 the assumed depth, and if so, this is in $\mathrm{m}$ ? Also, how was this new relationship developed, meaning using what data? Please be explicit.

We agree that this equation was perhaps confusing as originally presented. More information has been provided in WebPanel S1 lines 51 to 75, plus a new WebFigure S1. As well as describing the development of this equation and its limitations, we have noted that 
the form of the surface area - capacity relationship is similar to those developed for other regions of the world.

Line 40+ - More information is needed regarding STEDI, the model that supports this study. It sounds like a simple water budget model with only the parameters mentioned on lines 45-47? Is this correct? If so, please include that equation and any other governing equations of the model - and is meant specifically by terms such as "climate effects on the surface of the water body". Also, how was the model parameterized, and what objective functions (or loss functions) were used to evaluate the outputs? How well did the model perform? This is of key importance to Figure 3 . What are the primary uncertainties and limitations in using this model? Please add details here and a sentence or two to the main manuscript.

We agree that STEDI is central to some of the study's key conclusions, yet our original description of the model was perhaps not sufficiently detailed. Further description of the model and its core algorithm has now been fully articulated in WebPanel S1 lines 94 to 111. This also includes a clear statement of the key limitations of the model and the potential implications with respect to the major conclusions of our study in WebPanel S1 lines 143 to 146.

Webtable S1 - Spell out SAI in the caption.

This change has been made.

\section{Reviewer 1 comments to author}

The authors focus on downstream effects, but fish migration and thus migration barriers are twoway concerns. Also, degree of regulation is a poor surrogate measure of flow regime alterations (peak \& low flow magnitudes, frequencies, timing \& duration) (Poff et al. 2007 PNAS 104:57325737). These issues should be discussed as limitations of the degree of regulation measure as an estimate of impact.

Reviewer 1 is entirely correct that SAls may potentially have impacts on biodiversity both upstream and downstream. The revised manuscript includes a brief discussion of this point near line 83 .

Whilst we agree that no single metric can adequately describe the diverse ways in which dams can impact on downstream hydrology (e.g. cf. hydropower vs irrigation release strategies), the degree of regulation (DoR) metric has become a well accepted means of characterising the potential impact on downstream hydrology that can be mapped across diverse systems. This issue has been briefly mentioned near line 113, and again in WebPanel S1 line 8.

Lines 20, 69, 106. extent-not "scale"

This change has been made.

Lines 31. There are also substantial upstream impacts of SAls. See Leitao et al. (2018 Ecography 41:219-232)

As previously mentioned, some additional text describing impacts to biodiversity has been added near line 83 . The suggested reference has also been included on line 86 .

Lines 34, 167. that-not "which"

Lines 43, 217. Whereas-not "While" 
Lines 65. Also cite Walter \& Merritts (2008 Science 319:299-304)

Lines 86. Also called "tanks", "stock ponds", "mill ponds"

Lines 114. supports-not "supporting"

All the above minor changes have been made.

Lines 115. Define reach here. Is it segments (distance between tributaries or major geomorphic change) or sites (area above dams) or something else?

A definition of 'reach' has been added on line 128, and in more detail in WebPanel S1 line 80.

Lines 120-129. Somewhere, the authors should emphasize that small (first - third order) streams represent most ( $80 \%$ ) of the river/stream length of any river basin (Colvin et al. 2019).

We agree that this is an important issue, and perhaps most relevant to the section where we discuss how SAI effects on biodiversity tend to be biased toward smaller streams. Additional text as suggested has been added near line 164.

Lines 158-160. Summarize the Arkansas basin numbers here as well.

Results for the Arkansas River have been included in the revised manuscript.

Lines 183. refuges-not "refugia" Reserve refugia for large biogeographic areas.

Lines 218. substantial-not "significant" No p-value given.

Lines 220. condition-not "integrity" Integrity implies natural

Lines $245,260,284,286,298$. Use lower case in title.

Lines 306. Add a figure title.

All the above minor changes have been made.

Lines 311. Distinguish major dams from SAIs in both basins.

The intent was that the legend for panels (a) and (b) were also applicable to (c) and (d). Based on this comment, the figure has been modified so that each panel has a separate legend.

\section{Reviewer 2 comments to author}

This is a well written manuscript. Indeed, small dams and other man-made structures been largely ignored in riverine ecosystems.

We are grateful for this comment. The authors are keenly aware of the hydrological issues associated with small impoundments, and we are pleased that our enthusiasm seems to have been conveyed in this case. 
Small dams,artificial impoundments have big-impact: implications for hydrology and freshwater biodiversity

\section{Authors}

Robert Morden, University of Melbourne, Victoria, Australia; ORCID: 0000-0001-8293-5640

Avril Horne, University of Melbourne, Victoria, Australia; ORCID: 0000-0001-6615-9987

Nick Bond, Centre for Freshwater Ecosystems, La Trobe University, Wodonga, Victoria, Australia; ORCID: 0000-0003-4294-6008

Rory Nathan, University of Melbourne, Victoria, Australia; ORCID: 0000-0001-7759-8344

Julian D. Olden, School of Aquatic and Fishery Sciences, University of Washington, Seattle, Washington, United States; ORCID: 0000-0003-2143-1187

\section{Keywords}

Farm dams, farm ponds, small waterbodies, headwater streams, hydrological stress, freshwater biodiversity, unregulated streams

\section{Abstract}

Headwater streams are well known to be importantcritical for freshwater biodiversityecosystems. Global and continental studies consistently show major dams as a-dominant sourcesources of hydrological stress affectingthreatening biodiversity in the world's major rivers, but the-cumulative impact of veryimpacts from small waterbodies on downstream biodiversityartificial impoundments concentrated in headwater streams hashave rarely been acknowledged. Using the Murray Darling River basin (Australia) and the Arkansas River basin (USA) as case studies, we examine the hydrological impact of small artificial waterbodies. Their scaleimpoundments. The extent of impacttheir influence is very significant, hydrologically affecting between-altering hydrology in $280 \%$ and_ 380\% more waterways than when compared to major dams alone. Their hydrologicalHydrological impacts are biased towardconcentrated in smaller streams with (catchment areas less thanarea $<100 \mathrm{~km}^{2}$, which can harbour), raising concerns that the often diverse and highly diverse communities of aquaticendemic biota notfound in targer catchments. these systems may be under threat. Adjusting existing biodiversity planning and management approaches to deal with the diffuse nature of these waterbodies will be-address the cumulative effects of many small and widely distributed artificial impoundments presents a keyrapidly emerging challenge for the futureecologically sustainable water management.

In a nutshell:

- A number of recentRecent studies have highlighted the impactimplications of large dams on hydrological stressfor river hydrology and their potential implications for impacts on biodiversity. However, these studies have not consideredoverlooked the role of small artificial impoundments (SAls).

- Case studies are used to show that SAls can be a major source of hydrological stress. The downstream impact of SAls on flow regimes is similar to the impact of a single impoundment with the same aggregate capacity and watershed.

- Whereas major dams predominantly affect major rivers, SAls predominantly affect small waterways, including small headwater streams whichthat have been hailed as critical for freshwater biodiversity. 


\section{Introduction}

Headwater streams play a paramount role in maintaining hydrologic connectivity, harboring biodiversity, and supporting ecosystem integrity (Colvin et al. 2019). Despite this, debates continue over the implementation of policies and regulations seeking to protect headwater streamsthese waters from the-burgeoning human enterprise. In a recent high-profile example, the U.S. Environmental Protection Agency repealed its-a 2015 revision to the definitionupdate of the "-Waters of the United States", rescinding legal protection of manyStates' (WOTUS) rule would have qualified both perennial and smaller nonperennial waterways in the United States for water quality protections (Marshall et al. 2018). While, but implementation of this update was halted in 2019 and further scaling back of the definition of WOTUS was signed in 2020. Such regulatory actions in the United States and elsewhere, run in contrast to a large and growing body of literature supportssupporting the social and ecological value of headwater streams (Meyer et al. 2003; Clarke et al. 2008; Colvin et al. 2019), and mounting threats to these ecosystems caused by smaller dams and other regulating infrastructure has only recently come to light.

Past and planned construction of small-to-medium dams is unprecedented. Recent estimates report that the number of these structuressmall-to-medium on-channel dams (ca. 82,891) vastly outnumber large dams around the world, and that hundreds of thousands of additional small hydropower plants may be installed to meet future energy demands (Couto and Olden 2018; Lange et al. 2019). Indeed, many more dams are expected to be built in coming decades due to the increasing global demand for hydropower, water security, and food security (Zarfl et al. 2014). The widespread ecological damage and loss of important goods and services caused by large dams is well recognized (Sabater et al. 2018; Poff 2019; Tickner et al. 2020). One recent study concluded that close to two-thirds (63\%) of major global waterways have significantly reduced connectivity primarily caused by in-channel large dams, and to a lesser extent by a range of other anthropogenic factors such as urbanization and floodplain structures, while the remaining one-third (37\%) are considered 'free flowing' (Grill et al. 2019).

A conspicuous omission from all global assessments of river regulation by dams (eg. Nilsson et al. 2005; Zarfl et al. 2014; Grill et al. 2019) is that headwater streams-_-while not directly impacted by large on-stream dams-_- remain at significant risk from the impacts of smaller dams and artificial ponds within the catchment. These smaller diffuse sources of hydrologic interception (referred to here as small artificial impoundments or 'SAls', but often known as 'farm ponds', 'farm dams', or 'small storages' - refer Box 1 ) have received far less recognition. Awareness of the impact of smaller dams and waterbodies on downstream-hydrology and biodiversity has emerged in the-recent decadeyears, including the cumulative effects of dams forbuilt to support hydropower production (Walter and Merritts 2008; Couto and Olden 2018; Lange et al. 2019; Couto et al. 2021) and for agriculture practices (Renwick et al. 2006; Downing 2008; Nathan and Lowe 2012).

The scope of theseSAl impacts are challenging to characterize at a continental or global scale due to a lack of data regarding SAlstheir number and locations in many regions (Januchowski-Hartley et al. 2020). Consequently, they are often ignored in large scale studies and investigations into the effects of flow alteration on freshwater ecosystems, with research and policy attention instead focusing predominantly on large in-channel structures and major extractions. In doing so, such studies make an implicit assumption that the biggest ecological impacts arise from the biggestlargest individual extractions or impoundments, rather than considering the totality of hydrological stresses in operation, including those associated with the cumulative effects of SAls. 
biodiversity through multiple pathways, for example by altering habitat conditions (Agoramoorthy et al. 2016; Biggs et al. 2017), water quality (Renwick et al. 2006; Ibrahim and Amir-Faryar 2018), and waterway connectivity (Leitão et al. 2018; Barbarossa et al. 2020); here, we focus on the threat to downstream biodiversity using a hydrological measure of the degree of impoundment. We look to Australia and the United States to demonstrate how we continue to underestimate the risk posed to global biodiversity from hydrological alteration, particularly in headwater streams, by continuing to ignore the widespread-and ${ }_{2}$ growing number and cumulative impact of SAls.

\section{BoxPanel 1 - What are small artificial impoundments (SAIs)?}

The wide range of different terms for waterbodies distributed throughout catchments is a common source of confusion (Biggs et al. 2017). Small natural impoundments are usually called 'ponds' or 'lakes', whereas small artificial impoundments are called 'farm ponds', 'farm storages', of 'small storages', 'tanks', 'stock ponds', or 'mill ponds' and are usually constructed with a low earthen bank across a watercourse or landscape depression.

Local differences may also exist - in Australia small artificial impoundments are usually called 'farm dams'(Nathan and Lowe 2012), but other terms such as 'floodplain storage', 'catchment dam' or 'runoff dam' are sometimes used to help identify the primary source of the water. In Europe, the term 'small waterbodies' appears to be a more common label when referring to a wide range of features such as storages, mill ponds, and ditches (Biggs et al. 2017).

In this paper we adopt the term "small artificial impoundments" or "SAls" as it appears the most precise and least ambiguous terminology. SAls included in our analysis ranged over 400 -fold in size from as little as $250 \mathrm{~m}^{2}$ up to more than $100,000 \mathrm{~m}^{2}$. In our case study, SAls are typically constructed for agricultural and livestock purposes, with a smaller number managed for hydropower, recreation, aquaculture, or municipalpotable supply. Some examples of SAls from around the world highlighting their diversity of size and construction techniques are shown in Figure 1 below.

\section{Magnitude of hydrological stress}

Global assessments of the impacts of on-stream dams have reported the 'degree of regulation' (DoR), defined by the ratio of the total capacity of upstream storages with the average annual flow at a given location in the river network (Nilsson et al. 2005; Grill et al. 2019). DoR is a useful surrogate measure of potential threat to biodiversity, with dam induced flow changes shown to act synergistically with other impacts from dam modification, e.g. sediment flux, geomorphic alteration, floodplain disconnection and fragmentation of river corridors (Poff et al. 2007; Grill et al. 2014)Although DoR does not attempt to account for the nuances of hydrological regimes and dam operations, it does provide a simple and. While DoR is a simple metric and does not describe individual components of the flow regime, it does provide a consistent quantitative measure of the potential for hydrological stress that can be readily mapped (Lehner et al. 2011; Grill et al. 2014)at broad spatial scales.

To understand the role of SAls in contributing to hydrological stress throughout a catchment, the DoR concept was applied to two case studies, the Murray Darling basinRiver Basin, Australia, and the Arkansas River basinBasin, United States. These basins were selected as exemplars of the longstanding challenges facing global rivers subjected to SAls. The Murray Darling basin is the largest river basin in Australia covering more than one million square kilometres, supplying drinking water to more than three million people and generating roughly $40 \%$ of Australia's total agricultural production. The Arkansas River basin, the second longest tributary of the Mississippi River, 
encompasses close to a half million square kilometres, and supportingsupports substantial irrigated agricultural production.

The DoR was calculated for all reaches - defined as the segments between tributaries - in the river network for both case study basins, in the first instance considering only major on-stream dams, and then accounting for the additionpresence of SAls. A threshold to identify impacted rivers is difficult to estimate with any confidence. For comparative purposes, a DoR value of $16.7 \%$ has been adopted based on a recent global study of the impact of large storages (Grill et al. 2019). See Supporting Information for calculation methods.

Differences in estimates of degree of regulation are striking. In the Murray Darling River basinBasin, when considering only major on-stream storages (Figure $2 \mathrm{a}$ ) we find that around $10 \%$ of reaches by length are flow impacted (Figure 2b). But when SAls are included, the proportion of impacted streams in the basin almost quadruples to $37 \%$, with impacted streams represented across almost the entire basin. SAls only represent $7 \%$ of total storage capacity, yet their influence increases the relative length of impacted waterways by $380 \%$ compared to the extent of impacts from large storages. Similarly, in the Arkansas River basin, $3.5 \%$ of reaches by length are impacted by major onstream dams (Figure 2c), but when SAls are included this proportion nearly triples to $9.7 \%$ (Figure $2 \mathrm{~d}$ ). SAls only represent $0.03 \%$ of total storage capacity, yet they increase the relative length of impacted waterways by $280 \%$.

Climate is an important driver of the results reported here. Areas with mean annual rainfall higher than approximately $1000 \mathrm{~mm}$ have sufficiently high rates of runoff that the DoR rarely exceeds $16.7 \%$ even with high levels of SAI development. Conversely, areas with less than around $400 \mathrm{~mm}$ have such low runoff that even the presence of a small number of SAls could produce aresults in high estimates of DoR. However, these areas tend to have relatively low levels of SAI development, most likely because a combination of low runoff and high evaporation make open water impoundments impractical for most agricultural purposes.

Hydrological modelling was-also used to showrevealed that the effects of SAls on downstream flow regimes are broadly similar to the effects of large dams. Figure 3 shows the results of the hydrological modelling forUsing one Murray Darling River Basin site thereas an example, the effect on downstream flow regime of a hypothetical large dam was compared to a large number of SAls with the same aggregate capacity and watershed-(Figure 3). The overall percentage reduction in annual flow was somewhat higher for SAls than for a single large storage, but the net effect on flow exceedance and numbers of low flow days were very similar. Another four sites modelled in the same way showed comparable results (see Supporting Information for modelling methods and results for other catchments). In effect, if a large dam can be considered a source of flow regulation, then collections of SAls need tomust be consideredviewed as a form of 'distributed flow regulation'.

\section{Spatial comparison of impacted streams with biodiversity}

In both case study basins we found that SAls primarily affect smaller and headwater streams, and some instances these streams may have higher conservation priority because they support greater numbers of threatened species than waterways affected by large dams alone. This is particularly important, as first to third order streams make up to $80 \%$ of waterways in most basins (Colvin et al. 2019), and widespread threats to freshwater biodiversity globally (Tickner et al. 2020) highlight the need to protect and restore smaller and headwater streams -precisely these types of waterways.

Using the IUCN Red List of threatened species (IUCN 2019) as a key measure of biodiversity, we compared numbers of threatened species across waterways of different sizes (Figure 4) (see Supporting Information for analysis details). In both basins $\mathrm{S}_{L}$ almost all waterways impacted by major dams have a catchment area greater than $1000 \mathrm{~km}^{2}$. By contrast, approximately half of streams 
impacted by SAls have a catchment area less than $100 \mathrm{~km}^{2}$. For the Murray Darling River Basin, the proportion of impactedSAl-affected waterways with high numbers of threatened species $(>170)$ is much greater for smaller $\left(<100 \mathrm{~km}^{2}\right)$ compared to larger waterways $\left.\left(>10,000 \mathrm{~km}^{2}+\right) \cdot\right)(32 \%$ and $7 \%$ of waterways respectively). For the Arkansas River Basin, the trend is reversed $(21 \%$ and $50 \%$ of waterways respectively).

\section{Management challenges}

Across the globe there are ongoing efforts to restore biodiversity downstream of large dams. While these efforts are necessary to address the significant environmental impacts arising downstream from such structures (Tickner et al. 2020), our analysis suggests that river reaches downstream of large dams may potentially represent only a small fraction of all river reaches experiencing hydrologic stressif. SAls are also taken into account. This-vastly increased the length of waterways which are-potentially subject to hydrological stress-presents a major challenge. Catchment and waterway management agencies are already overstretched and addressing the needs of the additional waterways impacted by SAls is undoubtedly a substantial task.

A difficultChallenges to current policy-space-. While the case for controlling SAls to limit the risks to biodiversity may be clearapparent in some areas, there may also be a complex policy mosaic and considerable local resistance. Historically, in most parts of the world SAls could be built with little regulation or consideration of potential environmental impacts, although some jurisdictions have in recent years introduced controls on the construction of new SAls (Morris et al. 2019). This means that there is a tendency for many owners of SAls to consider them a 'right', and that any attempt to regulate or limit future development can be controversial (Horne et al. 2017). The large number of individual SAls requires consultation and engagement with thean equally large number of individual owners. Also, because SAls serve a variety of purposes (Nathan and Lowe 2012) they become entwined in a range of policy areas including agricultural water supply (Wisser et al. 2010), essential domestic water supply, sediment control (Renwick et al. 2006; Ibrahim and Amir-Faryar 2018), fire management, and in some cases provision of critical habitat and refugiarefuges (Agoramoorthy et al. 2016; Biggs et al. 2017; Chen et al. 2019).

The dangers of cumulative impacts-. When many individual landowners construct new SAlsfree from any significant regulatory control, their individual impacts may be negligible but their cumulative impacts can give rise to "the tyranny of small decisions" (Kahn 1966). Crucially, we have demonstrated that the storage capacity of an impoundment is not a good indicator of its potential impact, so a key challenge is to ensure that the cumulative impact of existing and future SAls is considered alongside larger dams (Couto and Olden 2018; Couto et al. 2021), other existing threats such as extractions, and other foreseeable future threats such as climate change and land use change (Athayde et al. 2019).

The challenges of an incompletelncomplete understanding of the problem-. Knowledge of the impacts of SAls requires, as a minimum, spatial data showingidentifying waterbodies as small as $\sim 200 \mathrm{~m}^{2}$. This information does not exist for most parts of the world (McManamay et al. 2018), although there are some exceptions such as the United States NHD Plus High Resolution dataset (Moore et al. 2019) and several state datasets in Australia. One of the highest resolution global datasets is HydroLAKES (Messager et al. 2016) showing 1.42 million waterbodies, but even this is insufficient as the smallest identified features are around $10 \mathrm{ha}$, which is approximately the upper limit of SAls. The scale of data processing required to capture large numbers of very small features from remote sensing data makes generating new datasets a complex and expensive task.

Insufficient modelling tools to account for impact and assess management actions-a. A further issue is the difficulty in demonstrating the benefits of any remedial actions over long 
implementation periods (King et al. 2017). While a range of modelling tools for SAls do exist (Habets et al. 2018), some adaptation of these tools will be required to track impacts and the benefits of any planned management intervention. There has been some success in this regard in Australia, for example the Murray Darling Basin Plan (Australian Government 2012) includes SAls in its annual accounting processes alongside major dams as part of the overall consumptive pool. Considerable work has been undertaken to develop new water accounting and modelling approaches to make this possible (Srikanthan et al. 2015; Morden 2017).

\section{Moving forward}

Many largerglobal and continental scale studies ignore the impacts of SAls, making an implicit assumption that the biggest ecological impacts arise from the biggest extractions or impoundments. This paper has highlighted the dangers of this assumption, showing that whilewhereas SAls have relatively small capacity, their large number means theand widespread distribution can result in substantial cumulative impacts-are significant and widespread. To ignore SAls is to underestimate the risk posed to biodiversity in smaller and headwater streams that are paramount to watershedfreshwater integrity (Colvin et al. 2019).

The impacts of SAls should be incorporated Moving forward, significant investments into all freshwater biodiversity and conservation planning. This includes the development of spatialdatasets identifyingnew information systems that catalog SAls and their characteristics, and theimplementation of environmental and hydrological monitoring required to demonstrate SAI impactsis necessary. It is only with this data that SAls can be considered alongside other forms of anthropogenic extractions and held accountable for the hydrological impacts they generate.

\section{Acknowledgements}

RM was funded by an Australian Government Research Training Program Scholarship and an ARC DECRA award (DE180100550). AH was funded through an ARC DECRA award (DE180100550). Thank you to-We thank two anonymous reviewers for helpful suggestions, and Lisa Lowe and Chloe Wiesenfeld for the use of theircontributing photos.

\section{References}

Agoramoorthy G, Chaudhary S, Chinnasamy P, and Hsu MJ. 2016. Harvesting river water through small dams promote positive environmental impact. Environ Monit Assess 188: 1-11.

ANCOLD. 2010. Register of Large Dams in Australia.

Athayde S, Duarte CG, Gallardo ALCF, et al. 2019. Improving policies and instruments to address cumulative impacts of small hydropower in the Amazon. Energy Policy 132: 265-71.

Australian Government. 2012. Water Act 2007 - Basin Plan 2012, Extract from the Federal Register of Legislative Instruments (28 November 2012).

Barbarossa V, Schmitt RJP, Huijbregts MAJ, et al. 2020. Impacts of current and future large dams on the geographic range connectivity of freshwater fish worldwide. Proc Natl Acad Sci U S A 117: 3648-55.

Biggs J, Fumetti S von, and Kelly-Quinn M. 2017. The importance of small waterbodies for biodiversity and ecosystem services: implications for policy makers. Hydrobiologia 793: 3-39.

BoM. 2012. Australian Hydrological Geospatial Fabric (Geofabric). 
Bunn SE, Kennard MJ, Bond NR, et al. 2014. Flow regimes and ecological assets. A technical report from the Ecological Responses to Altered Flow Regimes Flagship Research Cluster (SubProject 2). Melbourne, Australia.

Chen W, He B, Nover D, et al. 2019. Farm ponds in southern China: Challenges and solutions for conserving a neglected wetland ecosystem. Sci Total Environ 659: 1322-34.

Clarke A, MacNally R, Bond N, and Lake PS. 2008. Macroinvertebrate diversity in headwater streams: A review. Freshw Biol 53: 1707-21.

Colvin SAR, Sullivan SMP, Shirey PD, et al. 2019. Headwater streams and wetlands are critical for sustaining fish, fisheries, and ecosystem services. Fisheries 44: 73-91.

Couto TBA, Messager ML, and Olden JD. 2021. Safeguarding migratory fish via strategic planning of future small hydropower in Brazil. Nat Sustain: 1-8.

Couto TB and Olden JD. 2018. Global proliferation of small hydropower plants - science and policy. Front Ecol Env 16: 91-100.

Downing JA. 2008. Emerging global role of small lakes and ponds: little things mean a lot. Limnetica 29: 9-24.

Fowler K, Morden R, Lowe L, and Nathan R. 2015. Advances in assessing the impact of hillside farm dams on streamflow. Aust J Water Resour 19.

Geoscience Australia. 2006. GEODATA TOPO 250K series 3.

Grill G, Lehner B, Thieme M, et al. 2019. Mapping the world's free-flowing rivers. Nature 569: 21521.

Grill G, Ouellet Dallaire C, Fluet Chouinard E, et al. 2014. Development of new indicators to evaluate river fragmentation and flow regulation at large scales: A case study for the Mekong River Basin. Ecol Indic 45: 148-59.

Habets F, Molénat J, Carluer N, et al. 2018. The cumulative impacts of small reservoirs on hydrology: A review. Sci Total Environ 643: 850-67.

Hijmans RJ, Cameron SE, Parra JL, et al. 2005. Very high resolution interpolated climate surfaces for global land areas. Int J Climatol 25: 1965-78.

Horne AC, Morris CR, Fowler KJA, et al. 2017. Management options to address diffuse causes of hydrologic alteration. In: Water for the Environment: From Policy and Science to Implementation and Management. Elsevier Inc.

Ibrahim YA and Amir-Faryar B. 2018. Strategic insights on the role of farm ponds as nonconventional stormwater management facilities. J Hydrol Eng 23: 04018023.

IUCN. 2019. The IUCN Red List of Threatened Species. Version 2019-1. <http//www.iucnredlist.org> Downloaded 2 April 2019.

Januchowski-Hartley SR, Mantel S, Celi J, et al. 2020. Small instream infrastructure: Comparative methods and evidence of environmental and ecological responses. Ecol Solut Evid 1.

Kahn AE. 1966. The tyranny of small decision: market failures, imperfections, and the limits of economics. Kyklos 19: 23-47.

Karran DJ, Westbrook CJ, Wheaton JM, et al. 2017. Rapid surface-water volume estimations in beaver ponds. Hydrol Earth Syst Sci 21: 1039-50.

King A, Nally R Mac, Thompson RM, and Poff NL. 2017. Legacies, lags and long - term trends : Effective flow restoration in a changed and changing world.

Lange K, Wehrli B, Åberg U, et al. 2019. Small hydropower goes unchecked. Front Ecol Environ 17: 
256-8.

Lehner B, Liermann CR, Revenga C, et al. 2011. High-resolution mapping of the world's reservoirs and dams for sustainable river-flow management. Front Ecol Environ 9: 494-502.

Leitão RP, Zuanon J, Mouillot D, et al. 2018. Disentangling the pathways of land use impacts on the functional structure of fish assemblages in Amazon streams. Ecography (Cop) 41: 219-32.

Marshall JC, Acuña V, Allen DC, et al. 2018. Protecting U.S. temporary waterways (J Sills, Ed). Science (80- ) 361: 856-7.

McMahon TA, Peel MC, Lowe L, et al. 2013. Estimating actual, potential, reference crop and pan evaporation using standard meteorological data: a pragmatic synthesis. Hydrol Earth Syst Sci 17: 1331-63.

McManamay RA, Griffiths NA, DeRolph CR, and Pracheil BM. 2018. A synopsis of global mapping of freshwater habitats and biodiversity: implications for conservation. In: Pure and Applied Biogeography. InTech.

Messager ML, Lehner B, Grill G, et al. 2016. Estimating the volume and age of water stored in global lakes using a geo-statistical approach. Nat Commun 7: 1-11.

Meyer JL, Kaplan LA, Newbold D, et al. 2003. Where rivers Are born: The scientific imperative for defending small streams and wetlands. American Rivers, Sierra Club.

Moore RB, McKay LD, Rea AH, et al. 2019. User's guide for the national hydrography dataset plus (NHDPlus) high resolution.

Morden R. 2017. A new method of accounting for runoff dams. In: Syme G, Hatton MacDonald D, Fulton B, Piantadosi J (Eds). MODSIM2017, 22nd International Congress on Modelling and Simulation. Hobart, Australia.

Morris CR, Stewardson MJ, Finlayson BL, and Godden LC. 2019. Managing cumulative effects of farm dams in southeastern Australia. J Water Resour Plan Manag 145: 05019003.

Nathan R and Lowe L. 2012. The hydrologic impacts of farm dams. Australas J Water Resour 16: 7583.

Nilsson C, Reidy CA, Dynesius M, et al. 2005. Fragmentation and flow regulation of the world's large river systems. 308: 405-8.

Poff NL. 2019. A river that flows free connects up in 4D. Nature 569: 201-2.

Poff NL, Olden JD, Merritt DM, and Pepin DM. 2007. Homogenization of regional river dynamics by dams and global biodiversity implications. Proc Natl Acad Sci U S A 104: 5732-7.

Renwick WH, Sleezer RO, and Smith S V. 2006. Small artificial ponds in the United States: impacts on sedimentation and carbon budget. In: Proceedings of the Eighth Federal Interagency Sedimentation Conference (8thFISC), Reno, Nevada.

Rodrigues LN, Sano EE, Steenhuis TS, and Passo DP. 2012. Estimation of small reservoir storage capacities with remote sensing in the Brazilian Savannah region. Water Resour Manag 26: 87382.

Sabater S, Bregoli F, Acuña V, et al. 2018. Effects of human-driven water stress on river ecosystems: a meta-analysis. Sci Rep 8.

Sawunyama T, Senzanje A, and Mhizha A. 2006. Estimation of small reservoir storage capacities in Limpopo River Basin using geographical information systems (GIS) and remotely sensed surface areas: Case of Mzingwane catchment. Phys Chem Earth 31: 935-43.

Srikanthan R, Barua S, and Hafeez M. 2015. Estimating volume of water harvested by farm dams in Murray-Darling Basin. In: 21st International Congress on Modelling and Simulation. Gold Coast, 
Australia.

362

363

364

365

366

367

368

369

370

371

372

373

Stein JL, Hutchinson MF, and Stein JA. 2014. A new stream and nested catchment framework for Australia. Hydrol Earth Syst Sci 18: 1917-33.

Tickner D, Opperman JJ, Abell R, et al. 2020. Bending the curve of global freshwater biodiversity loss: An emergency recovery plan. Bioscience 70: 330-42.

USACE. 2019. National Inventory of Dams.

Venkatesan V, Balamurugan R, and Krishnaveni M. 2011. Establishing water surface area-storage capacity relationship of small tanks using SRTM and GPS. In: Energy Procedia. Elsevier.

Walter RC and Merritts DJ. 2008. Natural streams and the legacy of water-powered mills. Science (80- ) 319: 299-304.

Wisser D, Frolking S, Douglas EM, et al. 2010. The significance of local water resources captured in small reservoirs for crop production - A global-scale analysis. J Hydrol 384: 264-75.

Zarfl C, Lumsdon AE, Berlekamp J, et al. 2014. A global boom in hydropower dam construction. Aquat Sci 77: 161-70. 


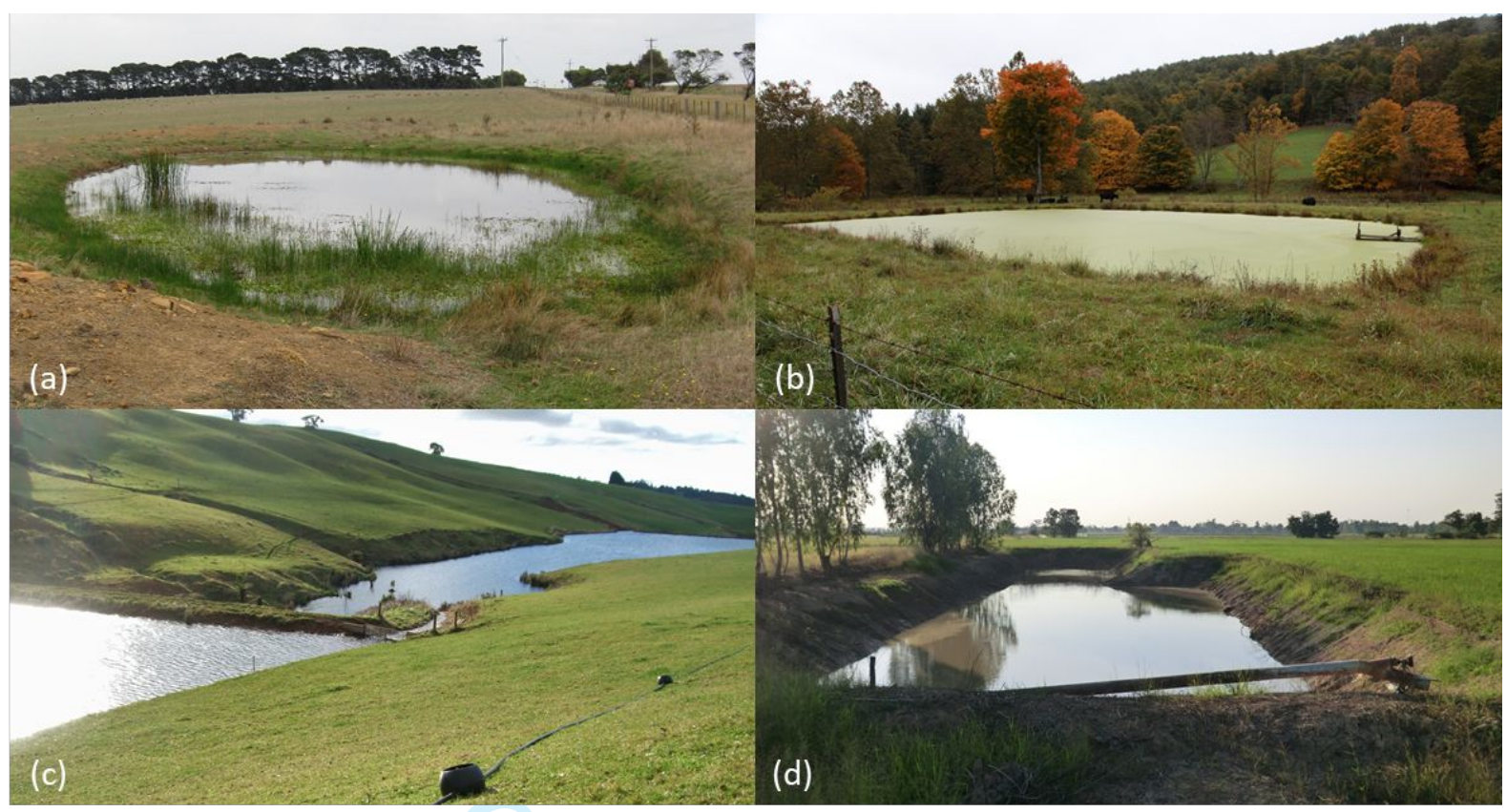

379 Figure 1:Figure 1: Examples of small artificial impoundments around the world (a) Victoria, Australia 380 (credit: Lisa Lowe), (b) Virginia, USA (credit: Chesapeake Bay Program, source: Flickr.com,

381 licencelicense: CC BY 2.0), (c) Tasmania, Australia (credit: Chloe Wiesenfeld) (d) Kampheng Phet, 382 Thailand (credit: François Molle; source: Flickr.com, licencelicense: CC BY 2.0). 
(a)

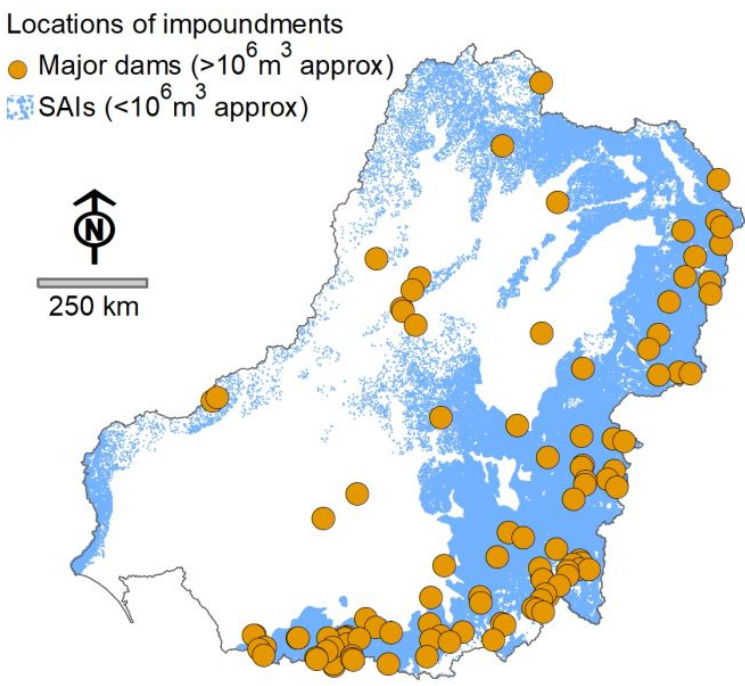

(c)

Locations of impoundments

Major dams $\left(>10^{6} \mathrm{~m}^{3}\right.$ approx $)$

SAls $\left(<10^{6} \mathrm{~m}^{3}\right.$ approx)

385

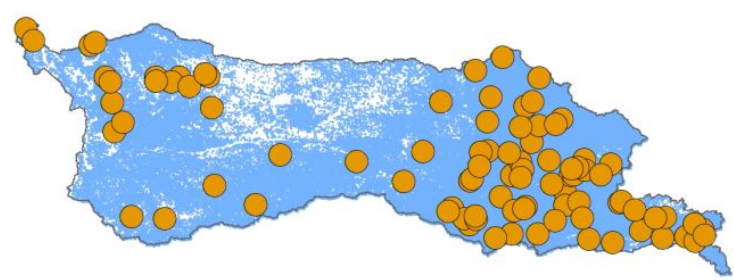

(b)

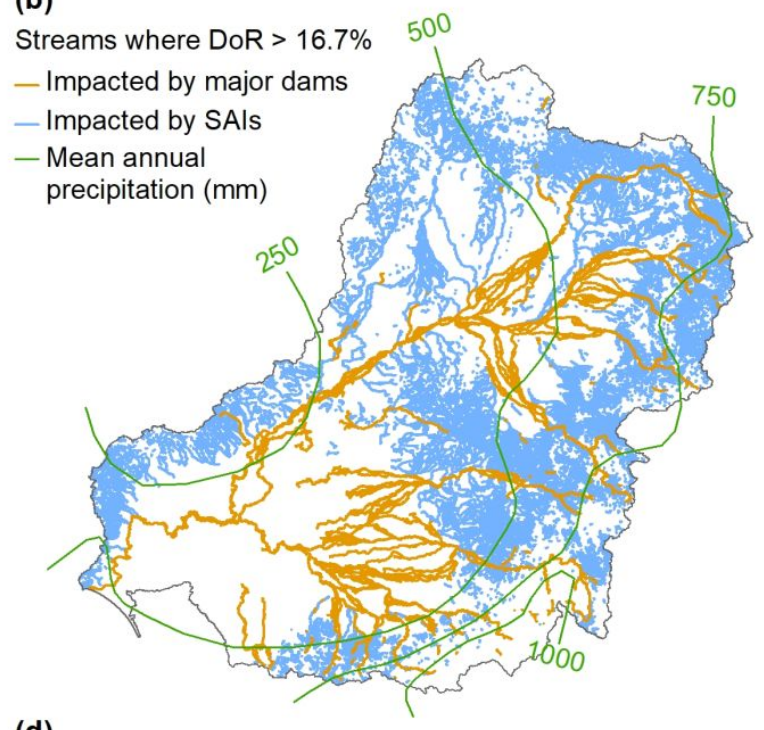

(d)

Streams where DoR $>16.7 \%$

- Impacted by major dams

_ Impacted by SAls

- Mean annual precipitation ( $\mathrm{mm}$ )

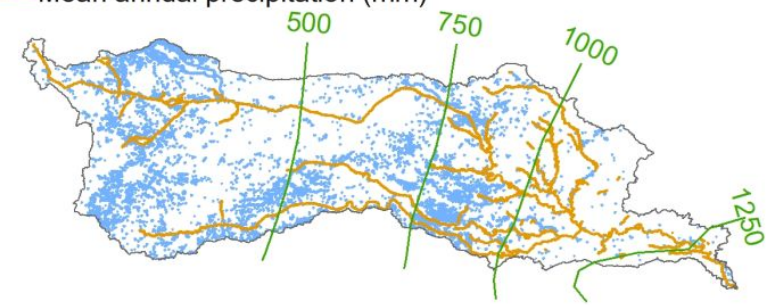

386 Figure 2: Impoundments and the downstream waterways in which they cause hydrologic stress (a) locations of major on-stream dams and small artificial impoundments (SAIs) in the Murray Darling River basin, (b) streams with a Degree of Regulation (DoR) greater than $16.7 \%$ in the Murray Darling River basin, (c) locations of the major on-stream dams and SAls in the Arkansas River basin, and (d) streams with a DoR greater than $16.7 \%$ in the Arkansas River basin. Precipitation data: WorldClim (Hijmans et al. 2005). 
(a) Total reduction in annual flows

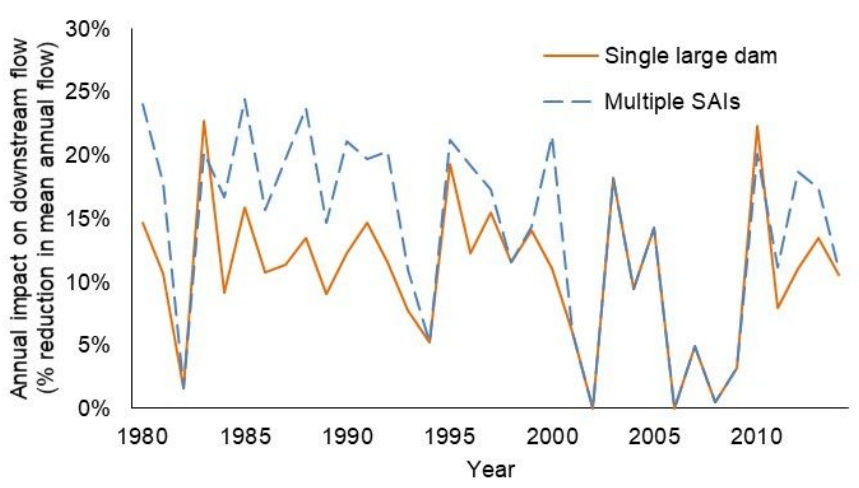

(b) Percent of low flow days

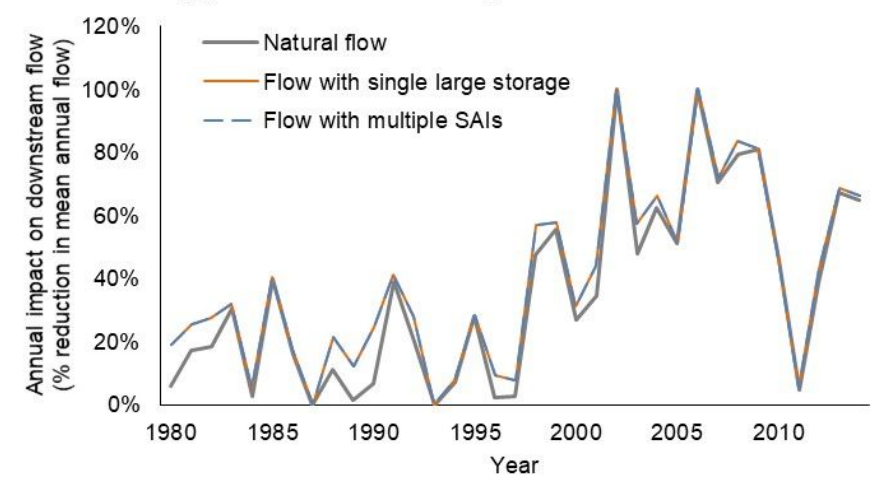

(c) Daily flow percentiles

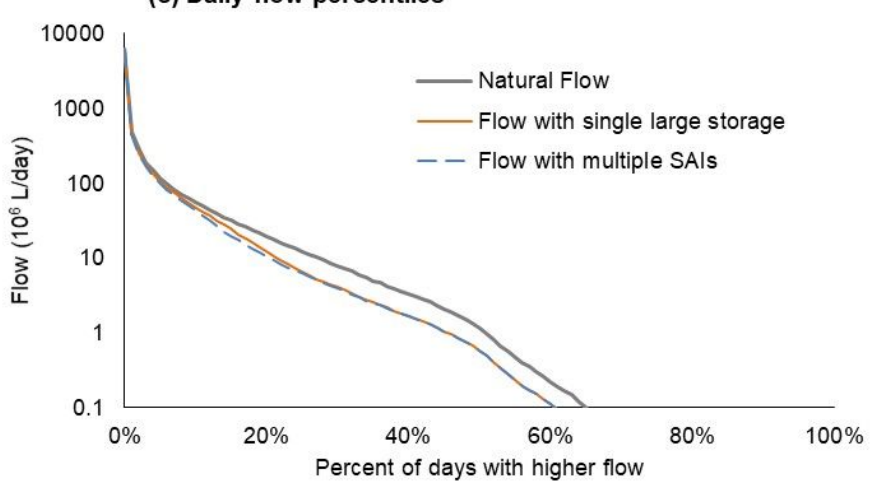

Figure 3: Comparison of impacts of a single large dam and multiple small dams, including (a) impacts on total annual flows, (b) impacts on percent of low flow days, and (c) impact on daily flow percentiles. Note that in panels (b) and (c) the blueorange line is mostly hidden by the redblue dash line. In each scenario, streamflow from a single gauge location (above shows Mt Ida Creek, Victoria, Australia, gauge 406226, catchment area $174 \mathrm{~km}^{2}$ ) was used as a hypothetical 'natural' flow, and the hydrological impact of impoundments was applied to this. The single large dam was set to capacity of $20 \%$ of mean annual flow (DoR $=20 \%$ ) with an upstream watershed area $50 \%$ of the gauged catchment. The SAlsmultiple small dams were set to capacity of $2500 \mathrm{~m}^{3}$ each, with the same aggregate capacity and watershed area as the single large dam. 
(a)

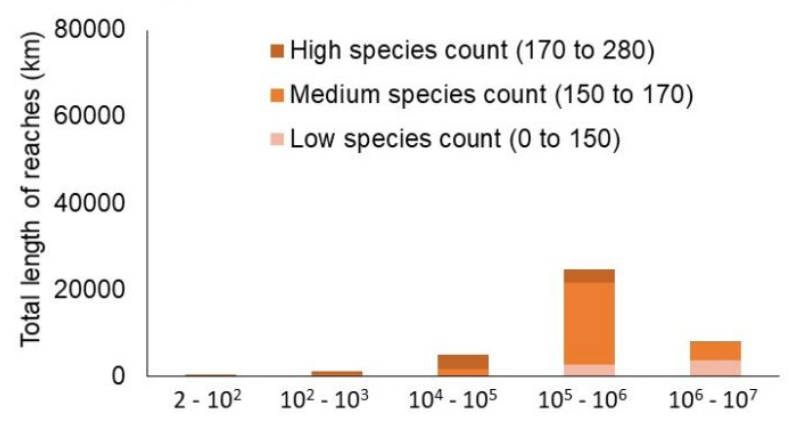

(c)

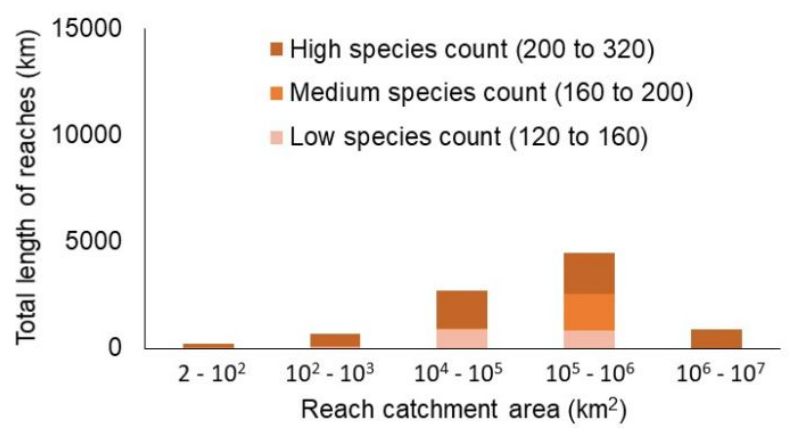

(b)

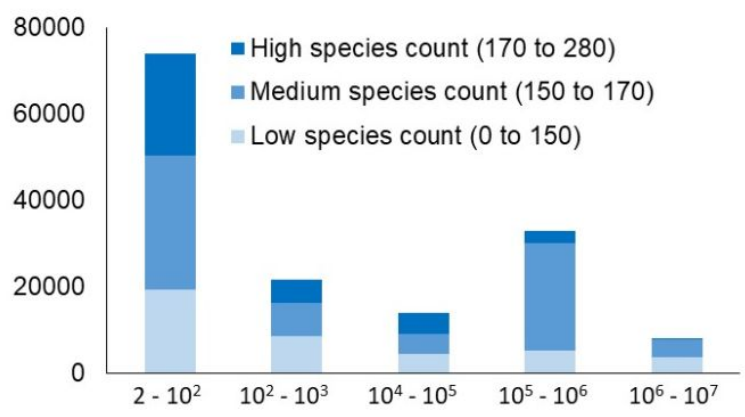

(d)

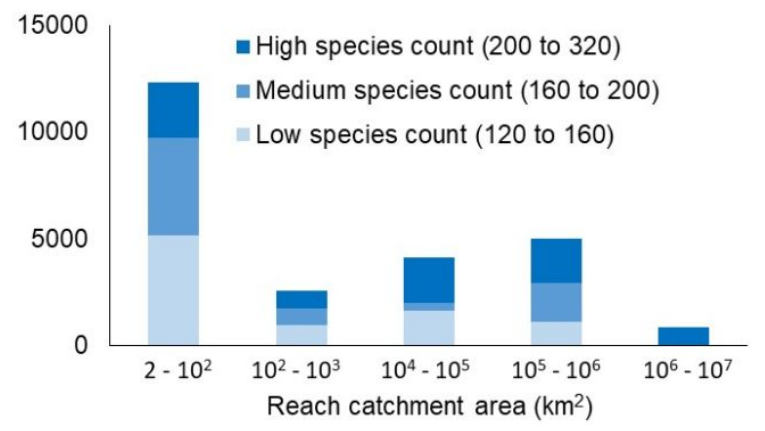

Figure 4: Total numbers of threatened freshwater species (IUCN red list) in waterways affected 411 (DoRdegree of regulation $>16.7 \%$ ) by large dams or large dams plus small artificial impoundments 412 (SAls-), aggregated by catchment area and reach length. (a) Murray Darling River basin with large 413 dams only (b) Murray Darling River basin with large dams plus SAls (c) Arkansas River basin with 414 large dams only (d) Arkansas River basin with large dams plus SAls. 


\section{WebPanel $1 \underline{\text { S1}}$. Details of analysis methods}

Calculating Degree of Regulation (DoR)

4 The Degree of Regulation (DoR) index is calculated for each reach in the network based on the

5 cumulative upstream storage relative to the cumulative average annual discharge, with units of

6 'years'. A DoR value of 0.5 therefore implies the total upstream storage volume is equivalent to $50 \%$

7 the mean annual runoff, while a DoR of 3 implies 3 times (ie. 300\%) the mean annual flow can be

8 captured or held in storages. Whilst having locally observed flow data is optimal for quantifying the

9 many different facets of flow alteration, DoR is still a strong surrogate at broader spatial scales

10 (Lehner et al. 2011; Grill et al. 2014). A number of thresholds have been used in the literature as indicative of potential downstream biological effects, ranging from 0.1 (Lehner et al. 2011) to 0.167 (Grill et al. 2019)Fo calculate the degree of regulation index (DoR), the total capacity of impoundments upstream of a given point in the river network is divided by the long term average annual streamflow at the same given point., which was the threshold adopted in the current study.

This index requires input data to characterize the impoundment locations and capacities, the river network, and the streamflow through the river network.
in WebTable S1 for each of the case study catchments.

Impoundment information

Not all waterbodies were included in calculations. In both case study catchments, natural waterbodies were excluded wherever they could be identified. Helpfully, the NHDPlus dataset (Moore et al. 2019) includes a field "FCODE" which clearly identifies many types of waterbodies. This field was used to specifically include only those features which were identified as a "reservoir" (FCODE $=43600)$, "reservoir for storing water" (FCODE=43613 to 43621), or "lake/pond" (FCODE $=39000$ to 39012). Other features were excluded as either natural waterbodies, or artificial waterbodies with no connection to natural drainage (eg. sewerage pondage, tailings, etc.).

In the Murray Darling basin, some large waterbodiesimpoundments were excluded if they were known to be off-stream storages because their primary source of water is extraction from another storage or waterway rather than runoff from their immediate upstream watershed. Also, SAls were excluded across large parts of the basin where the average slope of the surrounding terrain was $\underline{0.25 \%}$ ( 1 in 400 ) or flatter. In such areas, surface runoff is very unlikely to reach a waterway in natural circumstances, so small impoundments here are assumed to have no direct hydrological impact on a waterway.

In the Arkansas River basin continuous areas with average slope flatter than $0.25 \%$ do exist, but they are sufficiently small that filtering of SAls was not considered necessary.

The slope threshold of $0.25 \%$ was selected based on two criteria:

Topographic data showing waterways at a scale of 1:250,000 (Geoscience Australia 2006) In the Arkansas River basin, some large waterbodies were excluded based on information in the National Inventory of Dams. For example, some waterbodies were noted as being barrages in a river with little additional capacity beyond the river channel itself, while others were noted as being for flood

- indicates that there are large parts of the Murray Darling basin where first to third order streams rarely occur. These areas broadly coincide with a regional slope of approximately $\underline{0.25 \% \text { or flatter. }}$ ground or by building an enclosing embankment around the entire impoundment, whereas 
in steeper areas SAls are more commonly constructed by building an embankment across a waterway or a small fold in the landscape. This difference in construction technique underscores obvious differences in hydrological connectivity. While there is no distinct boundary between these two techniques, Inspection of detailed aerial imagery suggests that a slope of $0.25 \%$ provides a reasonable lower bound of where the latter technique occurs.

A range of data sources was used to estimate the capacity of impoundments. In the Murray Darling basin, capacities of major dams were assigned based on the published capacity in the Register of Large Dams in Australia (ANCOLD 2010), while the capacity of smaller waterbodiesimpoundments was estimated based on a previously published equation based on surface area (Fowler et al. 2015), and subsequently included as an attribute of each waterbody in the published spatial data (Bunn et al. 2014).

In the Arkansas River basin, capacities of major dams were assigned based on the published capacity in the National Inventory of Dams (NID) (USACE 2019). For the majority of small waterbodies, aimpoundments, volumetric capacities are not known. However, the NID does record the surface area and capacity of some smaller impoundments in the study area. A new relationship between surface area and capacity was developed based on the National Inventory of Dams using only dams in the Arkansas River basin smaller than $300,000 \mathrm{~m}^{2}$-or $1 \times 10^{6} \mathrm{~m}^{3}$, and where the average depth is greater than $0.3 \mathrm{~m}$. Thisthis data. Some filtering of the NID was required to obtain a meaningful relationship was then applied to all remaining SAls.as follows:

- To ensure the relationship was applicable to smaller impoundments, only those with valid surface area and capacity values smaller than $300,000 \mathrm{~m}^{2}$ or $1 \times 10^{6} \mathrm{~m}^{3}$ were included.

- A small number of dams were found to have very shallow average depth, suggesting an unusual structure such as a shallow flood control dam. Only those with average depth greater than $0.3 \mathrm{~m}$ were included.

- The NID records surface areas in units of acres. In some cases, this value is sometimes recorded as an integer, leading to significant rounding errors if the surface area is less than 10 acres. Dams with surface area recorded as an integer less than or equal to 10 acres were excluded.

The surface area and volumetric capacity of all remaining features in the NID in the Arkansas River basin are shown in WebFigure S1, leading to an empirical relationship as follows:

$$
\mathrm{C}=1.91 \times \mathrm{SA}{ }^{0.986} \text { where } \mathrm{C}=\text { capacity in } \mathrm{m}^{3} \text { and } \mathrm{SA}=\text { surface area in } \mathrm{m}^{2} \text {. }
$$

The power form of this relationship is conceptually similar to those developed for SAls in other locations globally, including Australia, India, Africa, North America, and South America (Sawunyama et al. 2006; Venkatesan et al. 2011; Rodrigues et al. 2012; Fowler et al. 2015; Karran et al. 2017). This relationship was applied to all SAls where a published capacity was not available. Although there is considerable scatter in the raw data shown in WebFigure S1 suggesting the capacity of an individual impoundment can only be estimated with low accuracy, it should nevertheless provide a robust estimate of the combined capacity of a large number of SAls.

\section{River network information}

Stream connectivity data was available through the Australian Hydrological Geospatial Fabric (AHGF) (BoM 2012) for the Murray Darling basin, and the National Hydrography Dataset Plus High Resolution (NHDPlus HR) (Moore et al. 2019) for the Arkansas River. Throughout this study, these datasets were used to define each waterway 'reach' usually as the segment between tributaries, but sometimes also breaking a reach where there was a significant geomorphological change such as a large waterbody. There were over 150,000 reaches and 335,000 reaches in the Murray Darling and Arkansas River basins respectively. 
All impoundments were assigned to a subcatchment and reach, and capacities were aggregated downstream and compared with mean annual flow to obtain the DoR. For both case study catchments, streams with a total upstream watershed less than $2 \mathrm{~km}^{2}$ were excluded from final results.

\section{Hydrological modelling}

We created simple hydrological models to compare the cumulative impacts on downstream flow regime due to large dams and SAls. Hydrological modelling of SAls is not common, but a handful of specialized algorithms and software packages do exist (Habets et al. 2018). For this analysis, we have used STEDI (Nathan and Lowe 2012; Fowler et al. 2015; Habets et al. 2018) which is based on a simple "fill and spill" water balance for each impoundment including inflows from the local upstream watershed, climate effects on the surface of the waterbody, anthropogenic extractions, and downstream spills.

Very briefly, STEDI is a simple "fill and spill" water balance model to estimate the filling behavior of SAls and their hydrological impact relative to a downstream point in the river network. STEDI requires no calibration or parameterization, it is a purpose-built tool for calculating a water balance for each SAI at each timestep and aggregating the overall impact of all SAls combined. The fundamental water balance equation applied at each timestep (in this case daily) is as follows:

$$
\triangle S T O R A G E=I N F L O W+\text { RAIN - EVAP - DEMAND - SPILL }
$$

The 'inflow' term is based on the flow at a downstream point in the river system, adjusted for respective catchment areas, usually obtained from observed flow records or separate rainfall runoff models. The 'rainfall' and 'evaporation' terms represent the climate acting directly on the surface of the water itself and are usually based on local climate records adjusted for the area of the water surface. The 'demand' term representing on-farm extractions is adjustable based on local conditions and is usually described as a set percentage of the impoundment capacity each year. The pattern of demand each timestep can be either a static value, a repeating annual pattern, or a longer timeseries of values.

Note that STEDI does not consider streamflow routing, in-stream losses, or seepage through the floor or walls of each impoundment. The model is able to provide a useful estimate of SAI impacts on downstream flow regimes in catchments where runoff generation can be assumed to be homogenous, and where routing and losses are not significant.

Two hypothetical scenarios were modelled for five catchments using STEDI. The first hypothetical scenario includes a single large storage in a catchment. In the second hypothetical scenario, the large storage is replaced by multiple $2500 \mathrm{~m}^{3}$ storages with the same aggregate capacity and the same aggregate inflows distributed equally between them. Each scenario was repeated for several different locations in eastern Australia. These scenarios are shown schematically in WebFigure S1.

Hydrological data for each location was obtained from a range of sources. Streamflow data for each location was obtained online from publicly available government data services, while rainfall and evaporation waswere obtained for the catchment centroid from the SILO database (http://www.longpaddock.qld.gov.au/silo). To best represent evaporation from the surface of each dam, Morton evaporation over shallow lakes was adopted (McMahon et al. 2013). Key hydroclimate statistics and scenario information for each modelled location is presented in WebTable S2.

Using the STEDI software, extraction from each storage is also modelled. In all cases, the long term average annual extraction was set equal to $50 \%$ of the dam capacity, with daily pattern of extraction based on a rolling 2 week average of net evapotranspration evapotranspiration (Morton's actual 
evapotranspiration minus rainfall). This was adopted as an approximation of water demands for irrigation.

Inflow for each modelled storage was based on the total natural flow for the catchment, adjusted based on the simple ratio of total catchment area to the storage's upstream watershed. In other words, flow was assumed to be generated uniformly across the catchment.

For each site and each scenario, the impact of storages was calculated on a daily basis for the period from January 1980 to December 2014. WebFigure S2 compares the annual impacts on streamflows for the single dam and multiple dam scenarios, as well as the impact on low flows.

WebFigure S2 demonstrates that the annual volumetric impacts due to a single large storage is the same order of magnitude as for multiple SAls, although in most catchments the impacts of SAls tend to be higher. The effects on percent of low flow days are the same for both scenarios. The combined surface areas of all SAls was greater than the surface area of a single storage even though they had the same overall capacity, which is an expected consequence of the typical geometry of artificial waterbodiesimpoundments. Higher rates of evaporation resulted in longer filling times for SAls, which is the most likely reason why the impacts of multiple SAls are often slightly higher with greater variability than single large storages.

This analysis clearly shows that the impact on the downstream flow regime is related to the combined capacity and upstream watershed areas of the storages. Small artificial waterbodiesimpoundments within a catchment behave as a form of 'distributed flow regulation'. Note that the limitations of the STEDI model do not affect this conclusion: although STEDI does not represent streamflow routing or in-stream losses, these catchment processes are likely to affect all modelled scenarios in a similar manner regardless of the nature of the impoundments.

\section{Threatened species analysis}

To assess where large dams and SAls may have hydrological effects on biodiversity, we used the IUCN Red List spatial data (IUCN 2019) which shows the approximate ranges for each endangered species. As well as being an important biodiversity measure in its own right, the presence of threatened species also provides a broad proxy for species richness more generally. WebFigure S3 presents a 'heat map' showing how the number of threatened species varies considerably across each case study catchment.

Considerable data filtering and processing was required, as the global dataset includes many tens of thousands of species, the majority of which are not relevant to this study:

- Initially, only freshwater species with ranges in the case study catchments were selected, because the focus of this study is specifically freshwater biodiversity.

- Some of the species range polygons were attributed as "Extinct" or "Possibly extant". These were excluded to ensure that the final species list only included those which are known to currently exist in the study areas based on observation.

- Lastly, all records which were attributed as being "data deficient" or "not evaluated" were excluded. Also, some species are represented multiple times in the database, so to eliminate any double counting the remaining species polygons were dissolved to ensure that only one polygon remained for each species.

The number of species present across each case study catchment was calculated based on the count of species polygons present at the centroid of each AHGF catchment in the Murray Darling basin (167,682 catchments), and each NHDPlus HR catchment in the Arkansas River basin $(897,087$ catchments). Although the species range polygons are often relatively coarse and do not have this 
182 level of spatial accuracy, the goal was to ensure that every catchment (and therefore every reach) 183 had a matching pair of values for DoR and number of threatened species.

184

185 WebReferences

186

187

188 


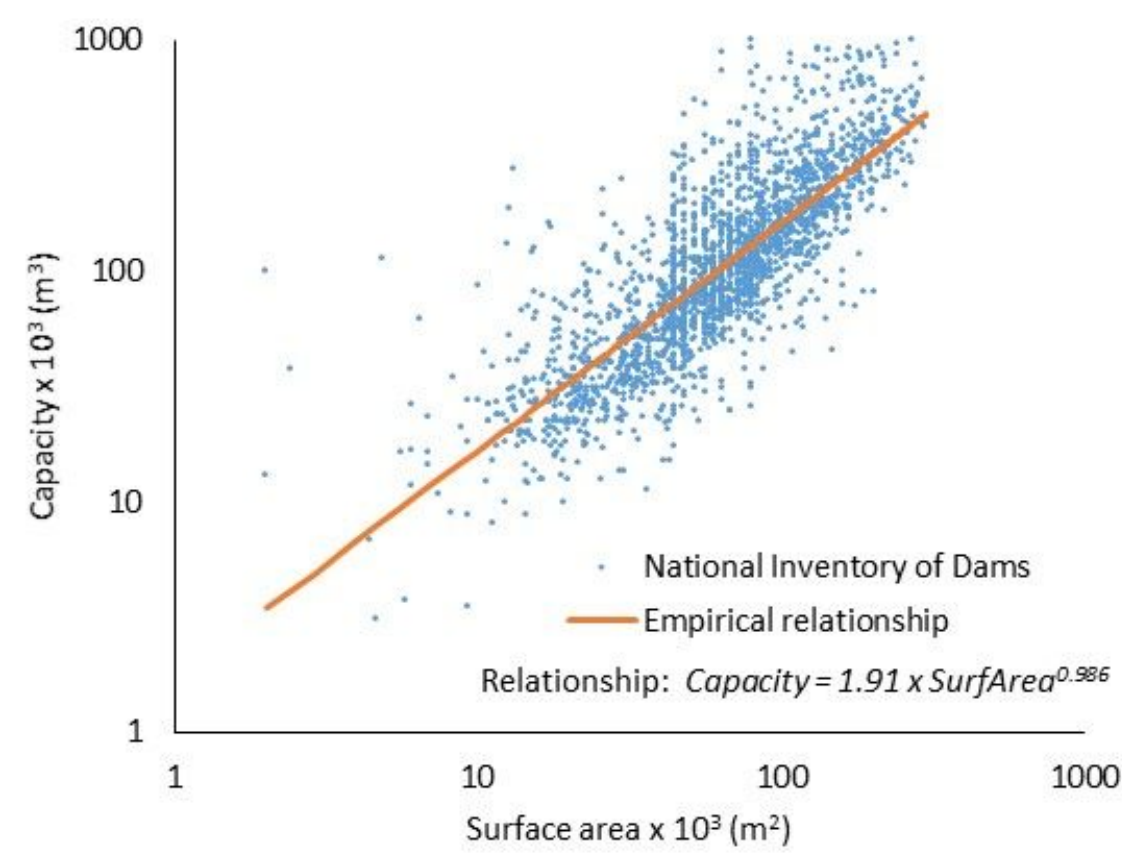

3

$4 \quad$ WebFigure S1: Developing an empirical relationship between the surface area and volumetric 5 capacity of impoundments included in the National Inventory of Dams (NID) in the Arkansas River 6 basin. Note that features were excluded if their capacity was greater than $300,000 \mathrm{~m}^{2}$, their surface 7 area was greater than $1 \times 10^{6} \mathrm{~m}^{3}$, or their average depth was less than $0.3 \mathrm{~m}$. Features were also 8 excluded if their surface area (acres) was published as an integer less than 10. 
1

R Morden et al. - Supporting Information

2

3

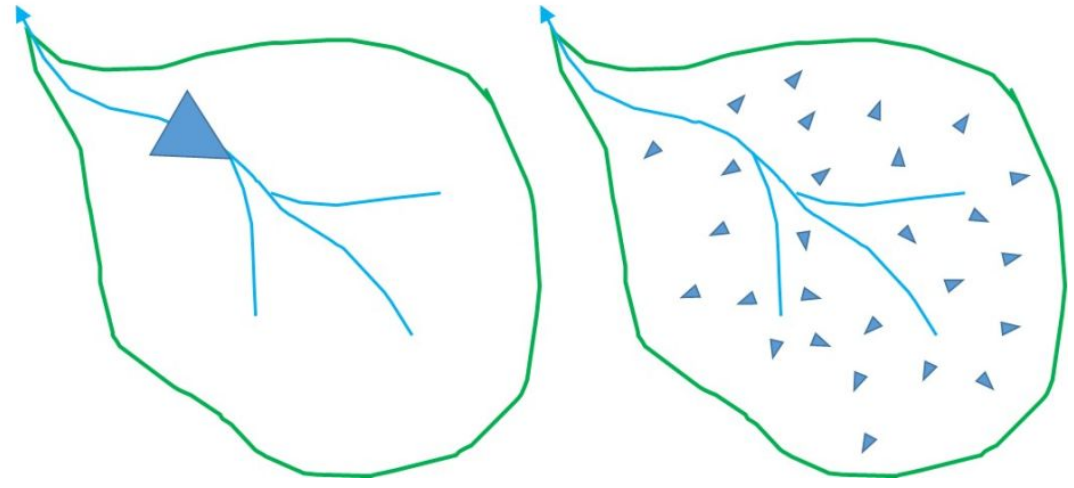

4 WebFigure S2: Schematic outline of the hydrological modelling scenarios using the STEDI small dam 5 modelling tool. On the left a single large storage with degree of regulation (DoR) $=20 \%$ is

6 impounding 50\% of the gaugedoverall catchment area, and on the right multiple $2500 \mathrm{~m}^{3}$ storages

7 with aggregate $\mathrm{DoR}=20 \%$ are impounding $50 \%$ of the gaugedoverall catchment area. 

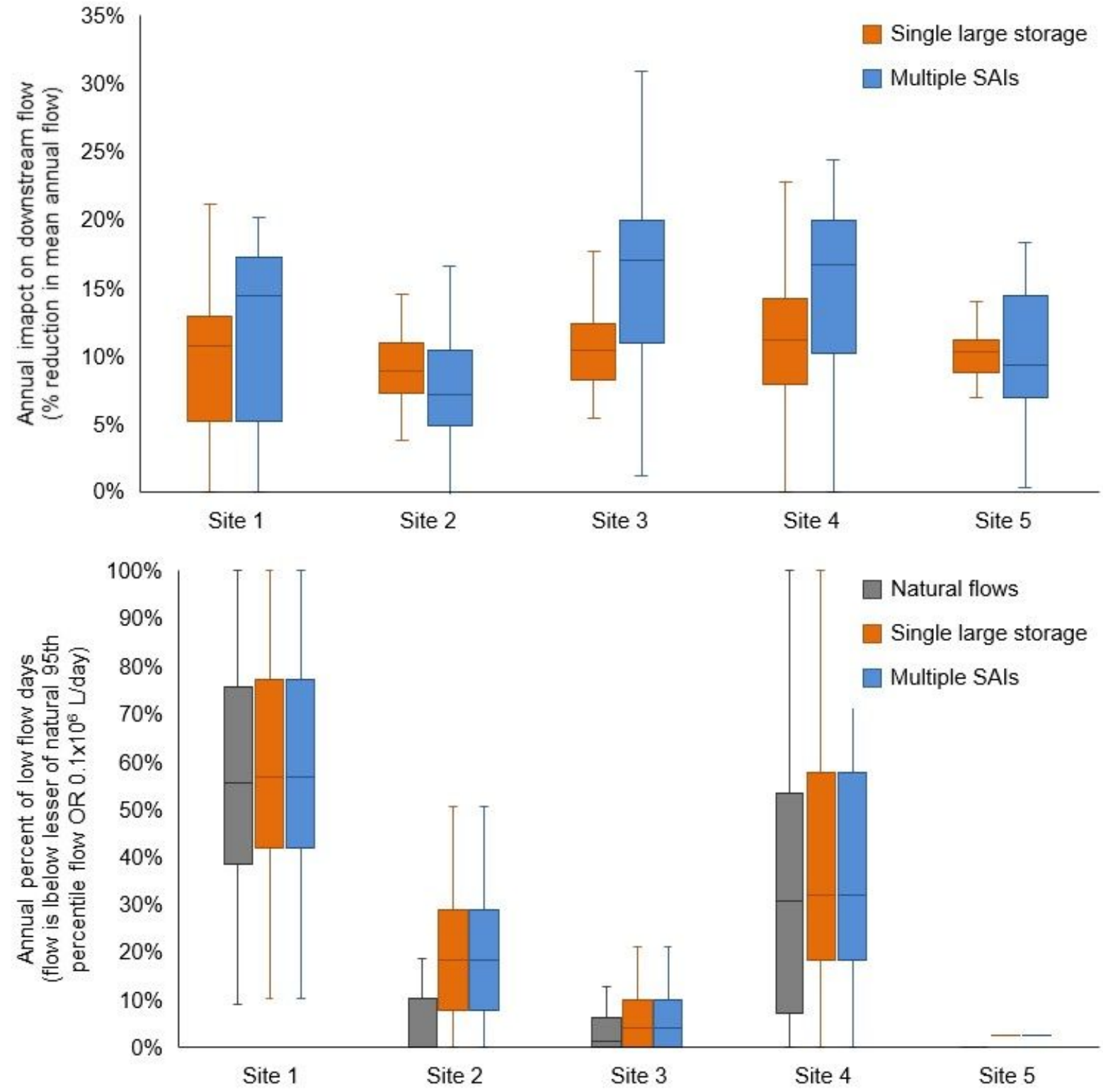

4 WebFigure $\$ 2$ S3: Impact in terms of annual reduction in flow (top panel) and annual percentage of 5 low flow days (lower panel), of a single large storage compared to multiple $2500 \mathrm{~m}^{3}$ storages with 6 the same overall capacity and upstream watershed, modelled over the period 1980 to 2014 . Boxes 7 represent the $25^{\text {th }}$ and $75^{\text {th }}$ percentiles with a median line, and whiskers represent the $5^{\text {th }}$ and $95^{\text {th }}$ 8 percentiles of annual impacts. 
1

\section{R Morden et al. - Supporting Information}

2

(a)

Number of threatened freshwater species

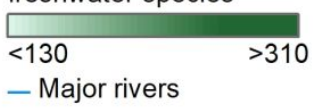

- Major rivers

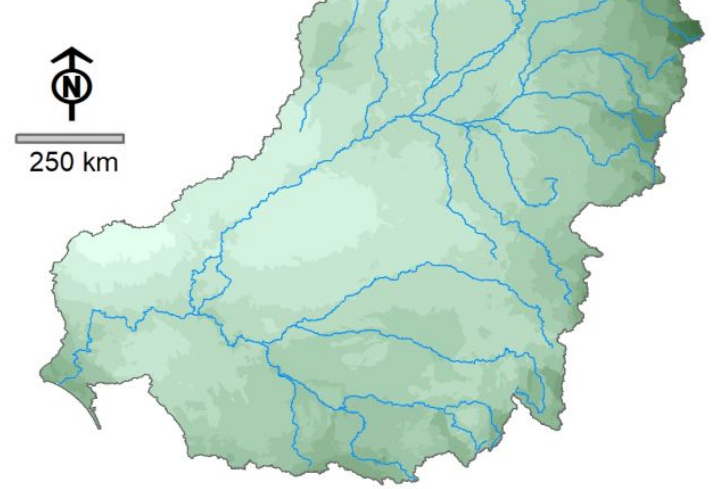

(b)

Number of threatened

freshwater species

$<130>310$

- Major rivers

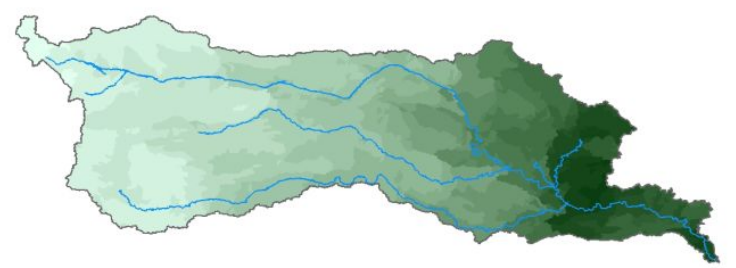

3

4 WebFigure S3: Heat map of numbersS4: Numbers of threatened freshwater species across a) the

5 Murray Darling basin and b) Arkansas River basin based on IUCN Red List data (IUCN 2019)-, showing

6 that threatened freshwater species are not distributed uniformly across each basin. Data is based on

7 the number of known freshwater species ranges present at all locations across each river network.

8

9

WebReferences

10

11 


\begin{tabular}{|c|c|c|c|}
\hline & & Murray Darling basin & Arkansas River \\
\hline \multirow[t]{2}{*}{$\begin{array}{l}\text { Dam } \\
\text { capacities }\end{array}$} & Major dams & $\begin{array}{l}\text { ANCOLD Register of large Dams in } \\
\text { Australia (ANCOLD 2010) }\end{array}$ & $\begin{array}{l}\text { National Inventory of Dams (USACE } \\
\text { 2019) }\end{array}$ \\
\hline & $\begin{array}{l}\text { SAIsSmall } \\
\frac{\text { artificial }}{\text { impoundments }} \\
\text { (SAIs) }\end{array}$ & $\begin{array}{l}\text { Murray Darling Aquatic Assets } \\
\text { Geodatabase v2.0 (Bunn et al. } \\
\text { 2014) }\end{array}$ & $\begin{array}{c}\text { New capacity/surface area relationship } \\
\text { based on National Inventory of Dams } \\
\text { (USACE 2019) }\end{array}$ \\
\hline \multicolumn{2}{|c|}{ Dam and SAI locations } & $\begin{array}{l}\text { Murray Darling Aquatic Assets } \\
\text { Geodatabase v2.0 (Bunn et al. } \\
\text { 2014) }\end{array}$ & $\begin{array}{l}\text { NHD Plus High Resolution (Moore et al. } \\
\text { 2019) }\end{array}$ \\
\hline \multicolumn{2}{|c|}{ River network } & $\begin{array}{l}\text { Australian Hydrologic Geofabric } \\
\text { (BoM 2012) }\end{array}$ & $\begin{array}{l}\text { NHD Plus High Resolution (Moore et al. } \\
\text { 2019) }\end{array}$ \\
\hline \multicolumn{2}{|c|}{ Mean annual streamflow } & $\begin{array}{c}\text { Australian Geofabric } \\
\text { Environmental Attributes (Stein et } \\
\text { al. 2014) }\end{array}$ & $\begin{array}{l}\text { NHD Plus High Resolution (Moore et al. } \\
\text { 2019) }\end{array}$ \\
\hline
\end{tabular}

WebTable S1: Data sources for Degree of Regulation calculations

4

\section{WebReferences}

6 
2

\begin{tabular}{|c|c|c|c|c|c|}
\hline & Site 1 & Site 2 & Site 3 & Site 4 & Site 5 \\
\hline Site name & $\begin{array}{c}\text { Concongella } \\
\text { Creek at } \\
\text { Stawell }\end{array}$ & $\begin{array}{c}\text { Franklin } \\
\text { River at } \\
\text { Toora }\end{array}$ & $\begin{array}{l}\text { Henry River } \\
\text { at Newton } \\
\text { Boyd }\end{array}$ & $\begin{array}{l}\text { Mount Ida } \\
\text { Creek at } \\
\text { Derrinal }\end{array}$ & $\begin{array}{c}\text { Running } \\
\text { Creek }\end{array}$ \\
\hline Gauge number & 415237 & 227237 & 204034 & 406226 & 402206 \\
\hline Mean annual flow $\left(10^{3} \mathrm{~m}^{3} / \mathrm{yr}\right)$ & 8185 & 21,675 & 46,050 & 10,365 & 29,600 \\
\hline Gauge catchment area $\left(\mathrm{km}^{2}\right)$ & 239 & 75 & 399 & 174 & 126 \\
\hline Mean annual rainfall (mm) & 537 & 1133 & 951 & 528 & 1169 \\
\hline Mean annual evaporation (mm) & 1163 & 998 & 1395 & 1224 & 1234 \\
\hline \multicolumn{6}{|c|}{ Single storage scenario } \\
\hline Capacity of single large storage $\left(10^{3} \mathrm{~m}^{3} / \mathrm{yr}\right)$ & 1637 & 4335 & 9210 & 2073 & 5920 \\
\hline Catchment area impounded $\left(\mathrm{km}^{2}\right)$ & 119.5 & 37.5 & 199.5 & 87 & 63 \\
\hline \multicolumn{6}{|c|}{ Multiple storage scenario } \\
\hline Number of $2500 \mathrm{~m}^{3}$ SAls & 655 & 1734 & 3684 & 829 & 2368 \\
\hline Catchment area impounded by each SAI $\left(\mathrm{km}^{2}\right)$ & 0.182 & 0.022 & 0.054 & 0.105 & 0.027 \\
\hline
\end{tabular}

3 WebTable S2: Key data inputs and characteristics for each site used in the hydrological modelling 4 with the STEDI small dam modelling tool 